\title{
The effect of the steel-concrete interface on chloride- induced corrosion initiation in concrete: a critical review by RILEM TC 262-SCI
}

\author{
Authors \\ Ueli M. Angst ${ }^{1}$, Mette R. Geiker ${ }^{2}$, Maria Cruz Alonso ${ }^{3}$, Rob Polder ${ }^{4,5}$, O. Burkan Isgor ${ }^{6}$, Bernhard \\ Elsener ${ }^{1}$, Hong Wong ${ }^{7}$, Alexander Michel $^{8}$, Karla Hornbostel $^{9}$, Christoph Gehlen $^{10}$, Raoul François ${ }^{11}$, \\ Mercedes Sanchez ${ }^{12}$, Maria Criado ${ }^{3,13}$, Henrik Sørensen ${ }^{14}$, Carolyn Hansson ${ }^{15}$, Radhakrishna Pillai ${ }^{16}$, \\ Shishir Mundra ${ }^{17}$, Joost Gulikers ${ }^{18}$, Michael Raupach ${ }^{19}$, José Pacheco ${ }^{20}$, Alberto Sagüés ${ }^{21}$. \\ 1 Institute for Building Materials (IfB), ETH Zurich, Stefano-Franscini-Platz 3, CH-8093 Zurich, Switzerland, Phone: \\ +41 4463340 24, Fax: +41 4463210 87, uangst@ethz.ch (* corresponding author) \\ 2 Department of Structural Engineering Norwegian University of Science and Technology (NTNU), NO-7491, \\ Trondheim, Norway' \\ Institute of Construction Science Eduardo Torroja-CSIC, Serrano Galvache 4, 28033 Madrid, Spain \\ RPCP, Gouda, The Netherlands \\ University of Technology, Delft, The Netherlands \\ School of Civil and Construction Engineering, Oregon State University, Corvallis, OR, USA \\ Department of Civil and Environmental Engineering, Imperial College London, Skempton Building, SW7 2AZ, \\ London, United Kingdom \\ Department of Civil Engineering, Technical University of Denmark (DTU), 2800 Kgs. Lyngby, Denmark \\ Norwegian Public Roads Administration, Directorate of Public Roads, Trondheim, Norway \\ Centre for Building Materials (cbm), Technical University Munich (TUM), Baumbachstr. 7, 81245 Munich, Germany \\ LMDC, INSA, UPS, Université de Toulouse, Toulouse, France \\ Department of Inorganic Chemistry and Chemical Engineering, University of Córdoba, 14071 Córdoba, Spain \\ Department of Materials Science and Engineering, University of Sheffield, Sir Robert Hadfield Building, Mappin St, \\ Sheffield S1 3JD, United Kingdom \\ 14 Danish Technological Institute, Gregersensvej, 2630 Taastrup, Denmark \\ 15 Department of Mechanical and Mechatronics Engineering, University of Waterloo, Waterloo, Ontario, Canada N2L \\ 3G1 \\ 16 Department of Civil Engineering, Indian Institute of Technology Madras (IITM), Chennai, TN 600036, India \\ 17 Division 7.4, Technology of Construction Materials, Bundesanstalt für Materialforschung und -prüfung (BAM), Unter \\ den Eichen 87, Berlin 12205, Germany \\ 18 Ministry of Infrastructure and Water Management, Rijkswaterstaat-GPO, Griffioenlaan 2, 3526 LA Utrecht, The \\ Netherlands \\ 19 Institut für Baustoffforschung, RWTH Aachen University, Schinkelstraße 3, 52056 Aachen, Germany \\ 20 CTL Group, Skokie, IL, USA \\ 21 Department of Civil and Environmental Engineering, University of South Florida, 4202 E. Fowler Avenue, Tampa, FL \\ 33620-5350, USA
}

This article has been prepared within a framework of RILEM TC 262-SCI. The article has been reviewed and approved by all TC members.

\section{TC Membership Chair: Ueli M. ANGST}

Deputy Chair: Mette R. GEIKER

TC Members: Johan AHLSTRÖM, Mark ALEXANDER, Ueli ANGST, Christian CHRISTODOULOU, Maria Joao CORREIA, Maria CRIADO, Maria Cruz ALONSO, Bernhard ELSENER, Raoul FRANÇOIS, Christoph GEHLEN, Mette GEIKER, Joost GULIKERS, Carolyn HANSSON, Karla HORNBOSTEL, Burkan ISGOR, Marc KOSALLA, Andraz LEGAT, Kefei LI, Victor Marcos MESON, Alexander MICHEL, Shishir MUNDRA, Mike OTIENO, José PACHECO FARIAS, Farhad PARGAR, Radhakrishna PILLAI, Rob POLDER, Michael RAUPACH, Alberto SAGÜÉS, Henrik Erndahl SØRENSEN, Luping TANG, David TREJO, Elsa VAZ PEREIRA, Talakokula VISALAKSHI, Hong WONG, Linwen YU, Yuxi ZHAO 


\begin{abstract}
The steel-concrete interface (SCI) is known to influence corrosion of steel in concrete. However, due to the numerous factors affecting the SCI - including steel properties, concrete properties, execution, and exposure conditions - it remains unclear which factors have the most dominant impact on the susceptibility of reinforced concrete to corrosion. In this literature review, prepared by members of RILEM technical committee 262-SCI, an attempt is made to elucidate the effect of numerous SCI characteristics on chloride-induced corrosion initiation of steel in concrete. We use a method to quantify and normalize the effect of individual SCI characteristics based on different literature results, which allows comparing them in a comprehensive context.

It is found that the different SCI characteristics have received highly unbalanced research attention. Parameters such as w/b ratio and cement type have been studied most extensively. Interestingly, however, literature consistently indicates that those parameters have merely a moderate effect on the corrosion susceptibility of steel in concrete. Considerably more pronounced effects were identified for i) steel properties, including metallurgy, presence of mill scale or rust layers, and surface roughness, and ii) the moisture state. Unfortunately, however, these aspects have received comparatively little research attention. Due to their apparently strong influence, future corrosion studies as well as developments towards predicting corrosion initiation in concrete would benefit from considering those aspects. Particularly the working mechanisms related to the moisture conditions in microscopic and macroscopic voids at the SCI is complex and presents major opportunities for further research in corrosion of steel in concrete.
\end{abstract}

\title{
Keywords
}

Steel-concrete interface; Interfacial transition zone; Durability; Corrosion; Inhomogeneity; Variability

\section{Introduction}

The steel-concrete interface (SCI) has frequently been claimed to play a major role in initiation of chlorideinduced reinforcing steel corrosion in concrete [1-11]. These studies generally focused on one particular characteristic of the SCI, such as the influence of a lime-rich layer at the steel surface or the presence of interfacial voids. However, given the complexity of the SCI and the variety of characteristics that may or may not occur locally [12], it remains unclear which are the most dominant influencing factors at the SCI that govern corrosion initiation. In this contribution, we summarize available literature documenting the effect of numerous characteristics of the SCI on chloride-induced corrosion initiation in concrete, and an attempt is made to study these individual effects in a comprehensive context. The aim is to elucidate the dominating characteristics and to identify areas where further research is needed.

This paper was prepared by members of RILEM TC 262-SCI, and is closely linked to a recent publication [12] that presented a systematic approach to describe the SCI in terms of local characteristics and their physical and chemical properties. Here, we focus on the effect of SCI characteristics on chloride-induced corrosion of carbon steel reinforcement in concrete. Coated, alloyed or high-strength steels as well as influences of corrosion inhibitors and electrochemical techniques (e.g. cathodic protection) are not considered. Note that we focus on corrosion initiation, which we consider as the transition of the steel from passivity to stable localized active corrosion. Literature on corrosion propagation (factors influencing the corrosion rate, corrosion-induced concrete cracking, etc.) are beyond the scope of this paper. We are aware that the community has struggled to agree on a definition of "corrosion initiation". Nevertheless, to avoid being forced to exclude a significant portion of the available literature, we have considered all relevant studies that, according to their authors, were designed to investigate chloride-induced corrosion initiation in concrete. 


\section{Methodology of reviewing the literature}

\subsection{Considered literature studies}

To quantify the impact of SCI characteristics on the initiation of chloride-induced corrosion, reported experimental results were collected which allow the corrosion susceptibility of steel in an alkaline system to be assessed in the absence or presence of certain SCI characteristics. This objective imposes a number of requirements to the studies in order to be considered suitable for our review. Here, we considered studies in which the steel specimen was exposed in an alkaline solution or in a cementitious system, and where the chloride concentration was systematically varied (added at different concentrations or increased over time). In order to quantify the susceptibility to corrosion initiation under these conditions, we looked for studies that either reported pitting potentials $\left(E_{\mathrm{pit}}\right)$, critical chloride contents $\left(C_{\text {crit }}\right)$, or that measured times to corrosion initiation in solutions $\left(t_{\mathrm{ini}}\right)$. The vast majority of the reviewed literature quantified the susceptibility to corrosion in terms of $C_{\text {crit. }}$. This parameter represents the chloride concentration in the concrete (or in a solution) at which the transition from passive steel to active corrosion occurs. In the literature, different methods are used to determine $C_{\text {crit }}$, and it is well-known that the chosen methodology affects the results [13]. Nevertheless, we consider $C_{\text {crit }}$ a suitable parameter for our review, mostly because of the broad acceptance of this concept to characterize "corrosion initiation" of steel in concrete $[13,14]$. In the literature, $C_{\text {crit }}$ is reported in terms of the free (dissolved) chloride ion concentration in the electrolyte (liquid phase) or in terms of total (bound and free) chlorides in concrete, mortar, or cement paste.

\subsection{Evaluation to quantify the effect of $\mathrm{SCl}$ characteristics}

We have used the following equation to quantify the effect of a particular characteristic, $x$, of the SCI:

$$
\text { Effect of } x: \quad E_{x, j}=\frac{c_{c r i t}^{x, j}-c_{c r i t}^{R e f, j}}{\min \left\{C_{c r i t}^{x, j} c_{\text {crit }}^{\text {Ref } j}\right\}}
$$

Here, $C_{c r i t}^{x, j}$ is the critical chloride content measured for the SCI characteristic $x$ reported in study $j$, and $C_{c r i t}^{R e f, j}$ is the critical chloride content of the reference case in the same study $j$. As an example, consider the case of the influence of mill-scale on the steel surface: Here, $C_{c r i t}^{x, j}$ would be $C_{\text {crit }}$ in the presence of mill-scale in a certain study $j$, and $C_{c r i t}^{R e f, j}$ would be $C_{\text {crit }}$ in the absence of mill-scale (reference case; e.g. removed by sandblasting) in the same studyj.

Because $C_{\text {crit }}$ values in the literature are known to be significantly affected by the test method used [13], we have chosen to normalize the effect of $x$ by adopting the minimum of $C_{c r i t}^{x, j}$ and $C_{c r i t}^{R e f, j}$. With this normalization, the application of eq. 1 to literature data allows the effect of different SCI characteristics $(x)$ determined in different studies $(j)$ to be compared. Additionally, the sign of $E_{x, j}$ illustrates if the effect is positive or negative, and the minimum in the denominator of eq. 1 ensures that negative and positive effects are equally scaled.

Consider that $n$ is the number of parallel specimens (replicates) used in a study. For a study with $n=1$ (following the example of mill-scale: one reported result for $C_{\text {crit }}$ with mill-scale, and one reported result for $C_{\text {crit }}$ without millscale), eq. 1 would produce one single value for the particular study. In many studies, however, replicate specimens were tested $(n>1)$, and thus, various results for both $C_{c r i t}^{x, j}$ and $C_{c r i t}^{R e f, j}$ were reported. The average effect of $x$ in a given study $j$ becomes:

$$
\left.\bar{E}_{x, j}=\frac{\bar{C}_{c r i t}^{x, j}-\bar{C}_{c r i t}^{R e f, j}}{\min \left\{\bar{C}_{c r i t}^{x, j}{ }^{\text {Refit }}, j\right.}\right\}
$$

Here, $\bar{C}_{c r i t}^{x, j}$ is the arithmetic mean of all $C_{c r i t}^{x, j}$ reported within one study $j$, and $\bar{C}_{c r i t}^{R e f, j}$ is the arithmetic mean of all $C_{c r i t}^{R e f, j}$ within study $j$. Eq. (3) was used to express the standard deviation of the effect of $x$ in study $j$ [15]:

$$
S D_{E_{x, j}} \approx \sqrt{\left(\frac{\bar{c}_{r r i t}^{x, j}}{\bar{c}_{c r i t}^{R e f, j}}\right)^{2} \cdot\left[\left(\frac{s D_{x, j}}{\bar{c}_{c r i t}^{x, j}}\right)^{2}+\left(\frac{s D_{R e f, j}}{\left.\left.\overline{\bar{c}}_{\text {crit }}^{R e f}\right)^{2}\right]}\right.\right.}
$$

Here, $S D_{x, j}$ is the standard deviation of all $(n) C_{c r i t}^{x, j}$ reported within one study $j$, and $S D_{R e f, j}$ is the standard deviation of all $C_{\text {crit }}^{\text {Ref } j}$ within study $j$.

Fig. 1 schematically shows how eqs. 1-3 were used to graphically represent the effect of a certain characteristic within different studies. This evaluation helped in assessing if there is agreement or disagreement concerning the 
effect of a certain characteristic $x$ within the available literature, both in a qualitative (positive vs. negative effect) and a quantitative manner (numbers on the ordinate).

\subsection{Remarks on the chosen methodology}

Note that we assumed that all the examined characteristics of the SCI, $x$, are independent. We are aware of the fact that this may not entirely be the case. However, it should be mentioned that most experiments were designed to study a particular parameter (e.g. the cement type) keeping all other parameters constant. Since it is practically impossible to experimentally provide systematic data with sufficiently high number of combinations of the wide variety of characteristics (full factorial experimental design), we believe there are currently no better alternatives to the above-presented approach. Valuable conclusions can be drawn from this review, but it is important to bear the limitations in mind and consider the outcome primarily as a guidance for further research rather than being directly applicable in engineering.

We did not exclude any studies because of potential weaknesses in experimental methodology, because an assessment of the quality of the different studies would be far from straightforward, especially considering the controversial discussions in the literature regarding criteria to detect (stable) corrosion initiation in concrete, or how to measure critical chloride content experimentally $[13,16]$. In other words, for the sake of a systematic and transparent methodology in evaluating the literature, we considered all available studies as equally relevant.

Note that the order of presenting information in the following sections is not according to their relevance, but follows the structure and conceptual treatment of the SCI presented in Ref. [12].

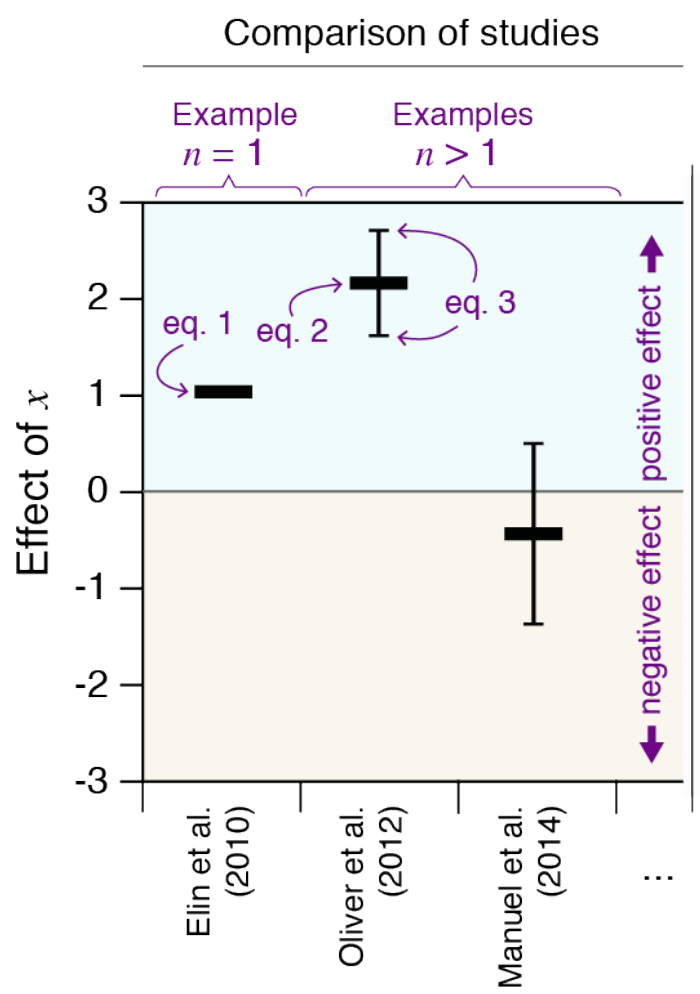

Fig. 1. Methodology used to quantify and compare the effect of an individual SCI characteristic $x$ on corrosion initiation in concrete according to different literature studies; $n=$ number of replicate specimens in a study. See section 2.2 for more explanations. 


\section{Documented influences}

\subsection{Reinforcing steel type}

\subsubsection{Metallurgy}

In the 1970s, thermomechanical strengthening processes (quenching and self-tempering) were developed and this rapidly phased out cold-work hardened reinforcing steel bars from the construction markets in many countries. Nowadays, quenched and self-tempered steels with a tempered martensite (TM) periphery and a ferrite-pearlite (FP) core (contributing to the desired strength and ductility) are widely used in practice. A number of investigations focused on the mechanical behavior of this new type of reinforcing steel. In one of the early of these works Rehm and Russwurm [17] indicated that "it is absolutely necessary to carry out corrosion tests". However, this issue has received very little research attention.

There are various studies in the literature focusing on the influence of steel microstructure on corrosion (generally on corrosion rate) in $\mathrm{CO}_{2}$ or in $\mathrm{pH}$-neutral chloride solutions, but with somewhat contradictory results [18-20]. The effect of inclusions on pitting corrosion initiation has also been studied, mostly in stainless steels [21]. However, limited literature data are available on the effect of metallurgy on chloride-induced corrosion initiation in alkaline environments. Trejo and Pillai [22, 23] compared $C_{\text {crit }}$ of conventional (ferrite-pearlite), micro composite (ferritic-martensitic), and stainless steels embedded in mortar. The ferritic-martensitic steels exhibited significantly higher $C_{\text {crit }}$ (approx. by a factor of 10) than conventional steels and similar chloride threshold as the 304 grade stainless steels. Angst and Elsener [24] compared reinforcing steels (in as-received condition) from 9 different countries with respect to their corrosion behavior in chloride-containing saturated $\mathrm{Ca}(\mathrm{OH})_{2}$ solution. The steel microstructure was identified as one of the major influencing parameters. $C_{\text {crit }}$ was statistically significantly lower (by a factor $>2$ ) for reinforcing steel that underwent thermomechanical strengthening (TM surface layer) compared to cold-work hardened steel (FP microstructure). Kumar [25] cut coupon specimens of TM and FP from the periphery and core, respectively, of a quenched and self-tempered steel rebar and immersed them in simulated pore solutions $(\mathrm{pH} \approx 13)$ with various chloride concentrations. The average $C_{\text {crit }}$ for $\mathrm{TM}$ coupons was slightly higher (by 11-16\%) than for FP coupons. Note, however, that the tested specimens were sections of steel bars, which may not be representative of the reinforcing bar surface. Further studies [26-28] investigated influences of steel metallurgy on corrosion in concrete, including dual-phase reinforcing steels, however, these studies did not report $C_{\text {crit }}$ or other quantified measures of corrosion initiation.

In short, little information on the effect of metallurgy on corrosion initiation of steel in concrete is available. Although the few available studies are contradictory, evaluating them [22-25] according to section 2 indicates an overall effect of the order of 3-4. At this stage, it can be concluded that the microstructure of the rebar surface is likely to play an important role in the corrosion initiation. However, further studies are needed in this area.

\subsubsection{Rebar geometry}

The geometry of rebars may influence corrosion initiation by modifying the SCI locally, namely due to the presence of ribs on the rebar surface, different diameters, or bent parts of the rebars. We expect that such effects would ultimately be related to microscopic level phenomena, including metallurgical influences (section 3.1.1), reinforcing steel surface (section 0), or interfacial voids (section 0). However, literature is not consistent. While Alonso et al. [29] reported negligible differences in $C_{\text {crit }}$ between ribbed and smooth rebars, Zafar and Sugiyama [30] found higher $C_{\text {crit }}$ for plain rebars (by a factor 2 compared to deformed rebars). Moreover, it was noted that for deformed bars, the corrosion started at ribs, whereas for plain bars the trigger for corrosion initiation was always an air void. Michel and Angst [31] found that, on largely rust-free surfaces, corrosion tends to initiate close to or on ribs, whereas on rusty rebars, corrosion does not preferably initiate on ribs (corrosion tests in alkaline solutions). In samples taken from engineering structures, Boschmann et al. [32] reported preferential corrosion initiation close to and on ribs for one concrete structure, while this was not observed in two other structures. Sandberg [4] found that corrosion initiated in approx. $70 \%$ of the cases in the deformed parts of reinforcing steel bars, particularly on the inside of the U-bend rebars. This was attributed to mechanical damage to oxide scales on the rebar during bending. In summarizing the literature, it is clear that the current level of documentation does not permit us to quantify the effect of the rebar geometry on corrosion initiation. 


\subsection{Reinforcing steel surface}

\subsubsection{Mill scale and pre-existing rust layers}

Different researchers reported [33-40] the influence of steel surface modifications (removing mill scale through sandblasting, polishing or pickling) on $C_{\text {crit. }}$ Some studies were undertaken in mortar or concrete $[36,37,40]$ and some in alkaline solutions [33-35, 38]. Figure 2 shows the evaluation of the data according to section 2.2. In most studies, the presence of these oxide scales promoted corrosion initiation; the effect (quantified according to eqs. 1 and 2) was generally in the range 0 to -2 . In one study [35] the effect was much more pronounced and approached -6 . In two studies $[33,40]$, however, it was found that the presence of the mill scale raised $C_{\text {crit. }}$ The mill-scale was reported to be particularly dense and continuous, which appeared to have a corrosion-protective effect. However, mill scale on most commercially available steel reinforcement is non-uniform, discontinuous, and contains cracks and crevices [41, 42]. Therefore, the presence of mill scale appears generally to promote corrosion initiation.

A number of studies [24, 37, 38, 42-44] suggested that the effect of pre-existing rust layers on corrosion initiation may be different from that of mill scale. Mohammed and Hamada [44] as well as Chen et al. [38] reported that $C_{\text {crit }}$ was lower in the presence of mill scale with additional rust than with mill scale alone. Angst and Elsener [24] compared rebars from different manufacturers and in different pre-rusted condition and reported that the degree of rust did not permit any reliable prediction of the susceptibility to chloride-induced corrosion. The influence of pre-formed rust scales was considered a weaker influencing factor than the manufacturing process or the metal microstructure. Al-Tayyib et al. [43] reported that pre-rusting did not promote corrosion initiation of rebars embedded in concrete.

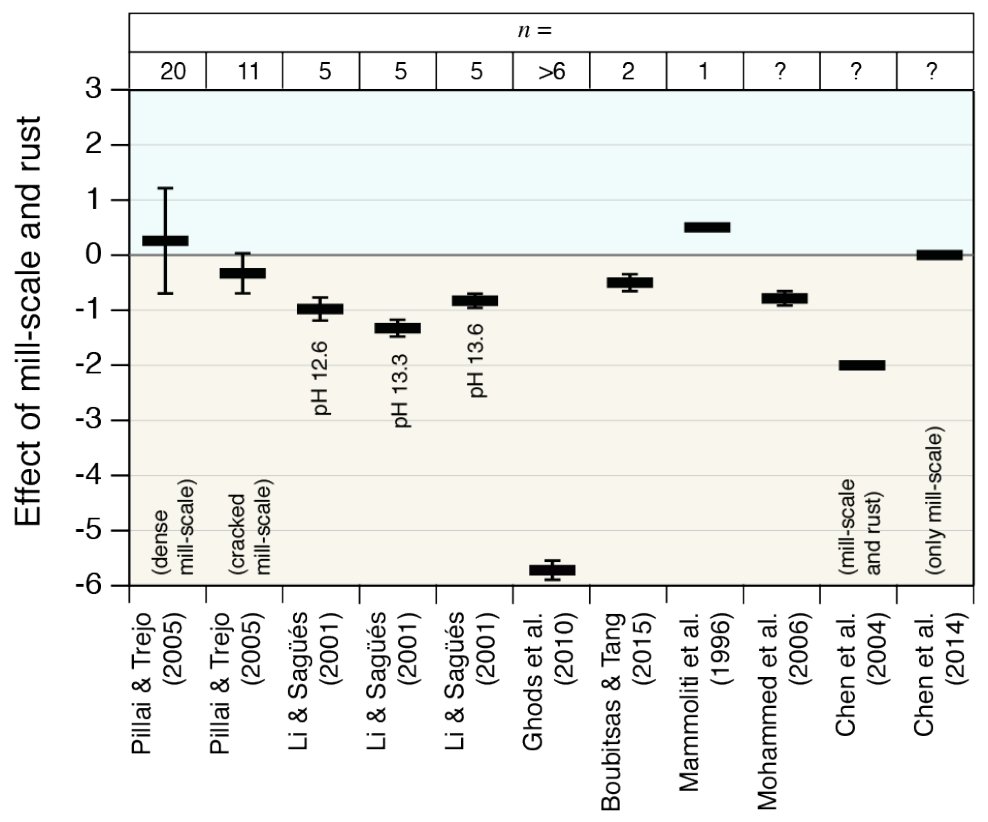

Fig. 2. Effect of mill scales and pre-existing rust layers on corrosion initiation [33-36, 38, 40, 44]. The presence of these scales generally favored corrosion initiation, as indicated by most data being located in the yellow area. The reference used to quantify the effect was the case without scales.

\subsubsection{Passive film}

Apart from possible effects of steel microstructure (e.g. inclusions) the passive film is the main barrier against pitting corrosion. The passive state of steel in alkaline environments such as cement-based concrete remains stable until chloride ions reach the steel surface. During prolonged exposure (ageing) of black steel to alkaline solutions or in concrete, the open circuit potential (OCP) asymptotically increases to more positive values, see [12] and Refs. cited therein. Several authors reported that ageing of the passive film (pre-passivation) of black steel in alkaline media results in an increase in the pitting potential, $E_{\text {pit }}$ [45-48]. The pitting potentials were measured in alkaline, chloride-containing solutions upon a given time of pre-passivation in chloride-free solutions of equal $\mathrm{pH}$. For sandblasted steel in synthetic pore solution an increase of the pitting potential of about $150 \mathrm{mV}$ was reported for a pre-passivation time of 30 days (Fig. 3) both for mildly corrosive conditions $\left(\mathrm{Cl}^{-} / \mathrm{OH}^{-}=1\right)$ and for severe conditions $\left(\mathrm{Cl}^{-} / \mathrm{OH}^{-}=25\right)[46,49]$. It is worth noting that the statistical distribution of the pitting potentials was very narrow 
for aggressive environments (high $\mathrm{Cl}^{-} / \mathrm{OH}^{-}$ratio) and relatively broad for mild conditions. In the case of ground or mechanically polished steel surfaces $[45,50]$ the effect of pre-passivation time on the pitting potential was found much more pronounced than for sandblasted steel $[46,49]$. Studies on pure iron showed that pre-passivation in chloride-free solution for $2 \mathrm{~h}$ resulted in a breakdown of the passive film after 60-80 h exposure to chlorides, while longer pre-passivation of 36 hours resulted in breakdown after 100-120 h [47]. Similarly, potentiostatic ageing (pre-polarization) under conditions where pitting does not occur $\left(E_{\mathrm{cor}}<E_{\mathrm{pit}}\right)$ tends to improve the resistance against later pitting corrosion $[51,52]$.

According to established corrosion theory [53], increasing $E_{\text {pit }}$ is associated with an increase in $C_{\text {crit. }}$ According to Fig. 3, $E_{\text {pit }}$ increases by roughly $40 \mathrm{mV}$ when steel is pre-passivated for one month instead of 1 week. From studies $[33,35,54]$, it is known that $E_{\text {pit }}$ decreases by about $400 \mathrm{mV}$ for an increase in chloride concentration by a factor of 10. Thus, as a first-hand estimate, it can be concluded that pre-passivating for 1 month instead of 1 week (or 1 week instead of $1 \mathrm{~d}$ ) increases $C_{\text {crit }}$ by a factor of 1.25 .

The association of $E_{\text {pit }}$ with $C_{\text {crit }}$ is also reflected in the observation that, all other conditions staying the same, $C_{\text {crit }}$ tends to increase when the steel potential prior to corrosion initiation is made more negative, either by macrocell coupling with other parts of the system or by applied polarization current $[55,56]$.

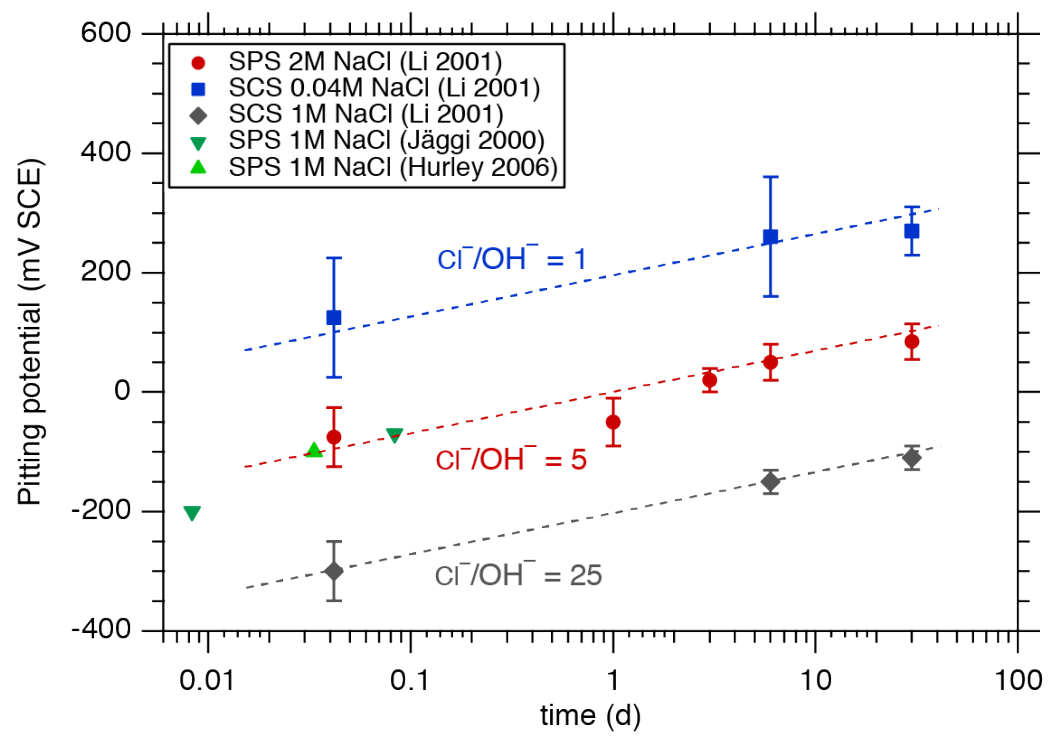

Fig. 3. Effect of the pre-passivation time on the pitting potential $E_{\text {pit }}$ (steel pre-passivated at the open circuit potential in alkaline synthetic pore solutions (SPS) and in saturated calcium hydroxide solution (SCS)). Experiments of $\mathrm{Li}$ (2001) pre-passivation in chloride-free solution, then measurement of $E_{\text {pit }}$ in corresponding chloride-containing solution [46]; experiments of Jäggi (2000) both pre-passivation and $E_{\mathrm{pit}}$ measurement in chloride-containing solution with $\mathrm{Cl}^{-} / \mathrm{OH}^{-}$ratio $=4$ [45]; experiments of Hurley (2006) both pre-passivation and $E_{\text {pit }}$ measurement in chloride containing solution for $1 \mathrm{~h}, \mathrm{Cl}^{-} / \mathrm{OH}^{-}=0.286[50]$.

\subsubsection{Steel surface preparation}

It has been widely reported that higher $C_{\text {crit }}$ were observed for rebars with modified surfaces, that is, through sandblasting, polishing or pickling than those in as-received conditions [33, 34, 40, 50, 57-60], as discussed in section 3.2.1. Moreover, literature indicates that the susceptibility to corrosion decreases with the degree of surface preparation. For instance, Mammoliti et al. [33] found that with an increasing degree of polishing (from grit 240 to grit 600 , thereby reducing the surface roughness), pitting potentials of carbon steel in $\mathrm{Ca}(\mathrm{OH})_{2}$ solution were shifted to more anodic values by at least $300 \mathrm{mV}$, occasionally even up to $600 \mathrm{mV}$, at various chloride concentrations. In similar tests, Figueira et al. [60] found a shift of $E_{\text {pit }}$ by approx. $300 \mathrm{mV}$ in anodic direction for carbon steel in various alkaline simulated pore solutions when moving from 500 grit SiC paper to $1 \mu \mathrm{m}$ diamond polishing suspension. Consistent with this, comparable relationships between $E_{\text {pit }}$ and degree of polishing (surface roughness) were reported from studies on stainless steels, e.g. [61], although the impact was generally less pronounced than in $[33,60]$. Following the reasoning presented in section 3.2 .2 , it can be inferred that such shifts in $E_{\text {pit }}$ due to decreased surface roughness have a dramatic influence on $C_{\text {crit. }}$ With the data reported in [33, 60], polishing to grit 600 instead of 240 or polishing with $1 \mu \mathrm{m}$ diamond polishing suspension instead of 500 grit, would raise $C_{\text {crit }}$ by roughly a factor of 10 . While it may be concluded that the steel surface preparation that goes 
beyond removing oxide scales has a strong effect on corrosion initiation in concrete, it should be noted, however, that this is based on only two studies for carbon steel.

As a final comment, we would like to highlight that in practice, the surface of steel reinforcement is typically not modified. However, corrosion sensors such as steel coupons used in structural monitoring often have sandblasted or polished surfaces. Additionally, such surface treatments may also be used in laboratory studies on corrosion of steel in concrete. Results from such studies as well as results from steel coupons exhibiting modified surfaces, e.g. in monitoring systems, should thus be interpreted with caution.

\subsection{Concrete microstructure and chemistry at the $\mathrm{SCl}$}

\subsection{1 w/b ratio}

The water/binder ratio (w/b) is known to be an important parameter in concrete. Its effects on compressive strength and transport, e.g. of chloride ions, are well documented. The effect of $\mathrm{w} / \mathrm{b}$ on corrosion initiation, on the contrary, is less well documented. $C_{\text {crit }}$ reported by [62-69], generally based on Portland cements, are compiled here and evaluated according to section 2.2 with the reference of $w / b=0.50$ (Fig. 4). Some publications did not include data for $\mathrm{w} / \mathrm{b}=0.50[66,68]$; in those cases, results were interpolated. Hansson \& Sørensen [62] and Breit [65] exposed mortar (w/b 0.40-0.60) with embedded steel in chloride solutions under anodic polarization, and, upon corrosion initiation, material from adjacent to the rebar was sampled and analyzed. Pettersson [63] and Li et al. [67] exposed mortar (w/b 0.40-0.60) with embedded steel to chloride solutions, either permanent or cyclic, and sampled material close to the steel upon electrochemical detection of corrosion onset. Sandberg et al. [64] derived what they call "engineering values" for submerged concrete from experiments (w/b 0.30-0.75). Oh et al. [66] admixed various chloride levels to concrete (w/b $0.35-0.55)$ and monitored corrosion potentials; after 30 days they sampled material around the steel and expressed pore solution and recorded the corroded area. Polder [68] exposed concrete (w/b 0.40-0.55) specimens to drying and wetting with chloride solutions and detected corrosion initiation with electrochemical measurements.

Summarizing these studies, both for concrete and mortar, either in natural exposure, under anodic polarization or with mixed-in chloride, the influence of $\mathrm{w} / \mathrm{b}$ on the susceptibility of steel to corrosion is relatively small. While there is general agreement that lowering $\mathrm{w} / \mathrm{b}$ below 0.5 slightly improves the resistance against corrosion initiation (increase of $C_{\text {crit }}$ up to approx. $30 \%$ ), the results for the effect of $\mathrm{w} / \mathrm{b}$ in the range above 0.5 are contradictory, with an overall negligible influence. Based on the currently available literature, it is concluded that the effect of w/b on the corrosion susceptibility of embedded steel is much less pronounced (and less clear) than the effect of w/b on mechanical and transport properties of concrete.

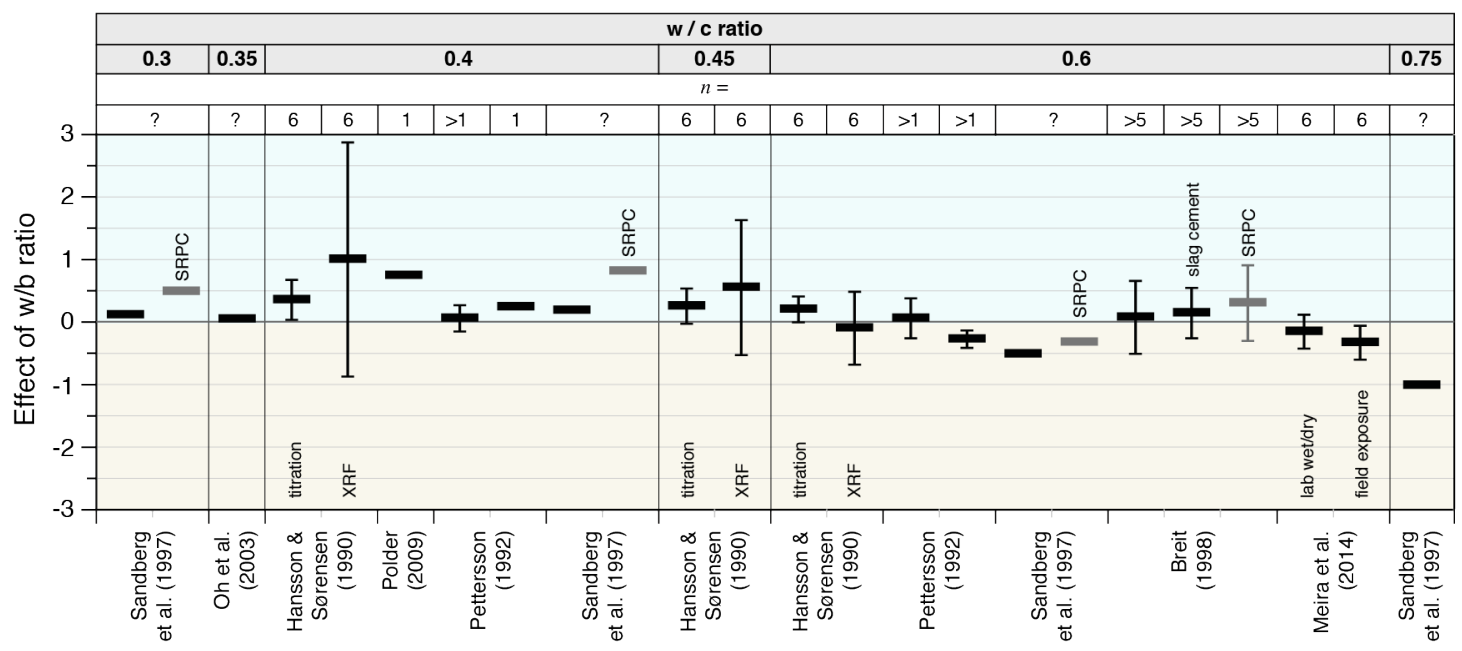

Fig. 4. Effect of $w / b$ ratio on corrosion initiation based on Refs. [62-69]. The reference case for this evaluation of the literature data $w a s, b=0.5$. For $w / b<0.5$ there is a slight tendency of improved resistance against corrosion initiation (blue area), while for $w / b>0.5$ the results are mixed with no clear effect. 


\subsubsection{Cement type}

Similar to $w / b$, cement type is also known to be an important parameter in concrete. For the purpose of this review, cement types have been broadly categorized into: (i) Portland cement (PC) blended with supplementary cementitious materials (SCMs) such as blast furnace slags (BFS), fly ash (FA) and silica fume (SF), and (ii) alkaliactivated cements (AAC), with BFS and FA as the main precursors.

PC blended with SCMs: A number of studies [57, 62, 63, 66, 70-74] reported $C_{\text {crit }}$ when using different SCMs as summarized in Fig. 5. It is apparent that the literature is ambiguous and even contradictory since for all investigated SCMs (FA, BFS, SF) both positive and negative effects have been reported. Given the ambiguous nature of reported data on the influence of cement type on $C_{\text {crit }}$, it is difficult to conclusively state whether the blending of SCMs with PC has a positive or a negative effect on corrosion initiation. The $\mathrm{C}_{3} \mathrm{~A}$ content of $\mathrm{PC}$ has a significant impact on the ability of the binder to interact with chlorides and form Friedel's salt. As a result, increasing the $\mathrm{C}_{3} \mathrm{~A}$ content in $\mathrm{PC}$ increases $C_{\text {crit }}$ when the latter is expressed as total chloride content [63, 75] (Fig. $5)$. Fig. 5 shows that most studies generally agree that the overall effect of the cement type, including different $\mathrm{SCMs}$ and differences in $\mathrm{C}_{3} \mathrm{~A}$ content, is moderate (in most cases, the absolute effect is $<1.5$ ).

Alkali-activated cements: Corrosion initiation in AACs is a much less studied topic in comparison to OPC and blended cements. Studies investigating $C_{\text {crit }}$ in alkali-activated FA [76] and FA/BFS blended systems [77] typically found $C_{\text {crit }}$ to depend primarily on the ratio $\left(\mathrm{SiO}_{2} / \mathrm{Na}_{2} \mathrm{O}\right)$ of the activator used. In the case of alkali-activated BFS, several studies have reported reducing conditions at the SCI due to the presence of sulfides in the pore solution $[78,79]$, which is claimed to influence, at least for some time, the corrosion performance [80, 81]. Unfortunately, no studies were identified that allow to quantify the effect of AAC with the methodology used in this review, generally because no reference data (specimens with OPC) were studied in the reviewed publications.

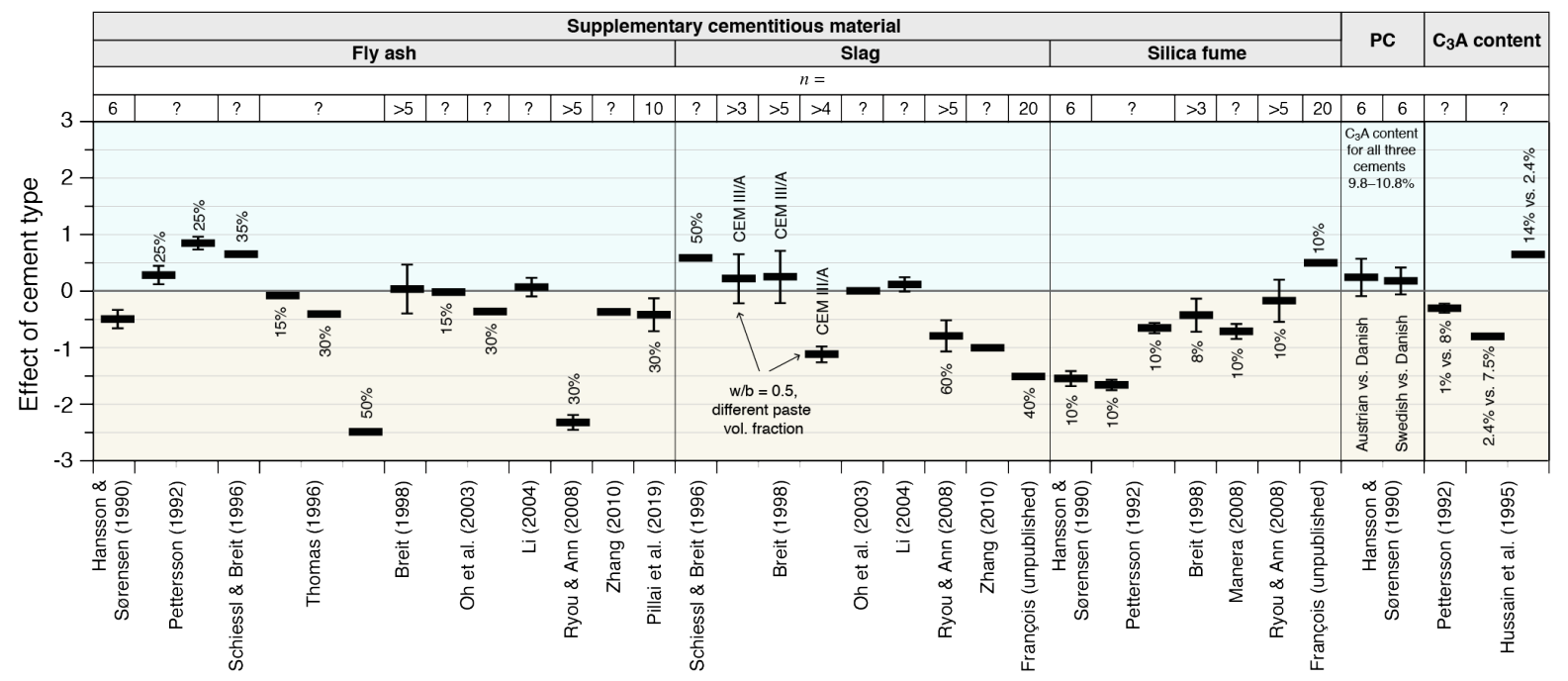

Fig. 5. Effect of cement type on corrosion initiation based on total $C_{\text {crit }}$ reported in $[57,62,63,66,70-75]$. The reference case was always $\mathrm{PC}$; for the effect of $\mathrm{C}_{3} \mathrm{~A}$ content, the reference $\mathrm{C}_{3} \mathrm{~A}$ content was $\sim 8 \%$. The percentages given indicate the amount of SCM or the amount of $\mathrm{C}_{3} \mathrm{~A}$ in the binder, respectively. The results are ambiguous, but in general the absolute effect of cement type appears to be $<1.5$. 


\subsection{Macroscopic interfacial concrete voids at the SCI}

\subsubsection{Interfacial air voids}

Interfacial air voids occur when entrapped or entrained air bubbles in fresh concrete rise up during compaction and become trapped beneath reinforcing steel bars. Most (if not all) studies have focused on the effects of entrapped rather than entrained air voids on corrosion initiation.

Various studies have noted that corrosion of embedded steel reinforcement tends to initiate at locations where air voids are present at the steel-concrete interface [3, 82-88]. However, in many publications it remained unclear whether corrosion initiated at the steel surface exposed in the actual air void or at the steel surface exposed in the cementitious matrix adjacent to it.

Several authors $[83,85,88]$ found that interfacial air voids significantly reduced $C_{\text {crit }}$ (Fig. 6). In these studies, the authors varied the amount of compaction voids (entrapped air) in $150 \mathrm{~mm}$ concrete cubes with a single rebar at $15 \mathrm{~mm}$ cover. The specimens were sealed-cured for 28 days, then saturated with water and submerged in $4 \mathrm{M}$ $\mathrm{NaCl}$ solution at $30^{\circ} \mathrm{C}$. Upon initiation of corrosion, as indicated by a galvanic current rise, the specimens were split and the steel surface observed. Visual examination of the SCI indicated that corrosion tends to initiate at locations adjacent to entrapped air voids. Furthermore, for a range of binder types, an increase in air void content from 0.2 to $2 \%$ led to a decrease in $C_{\text {crit }}$ from 1.2 to $0.2 \%$ by mass of binder. The most pronounced change occurred below $1 \%$ air content. However, concrete with air contents below $1 \%$ are rare in engineering practice. Between 1 and $2 \%$ entrapped air content, which is the range in which most concretes in practice are expected to be, the impact of entrapped air void content on $C_{\text {crit }}$ was found to be approx. a factor of 2 . For entrapped air contents above approx. $1.5 \%$, the influence on corrosion initiation was negligible. The results of these studies indicate that the effect of interfacial air voids is greater than that of the cement type, at least at relatively low air void contents. Similar findings were also reported in [87, 89].

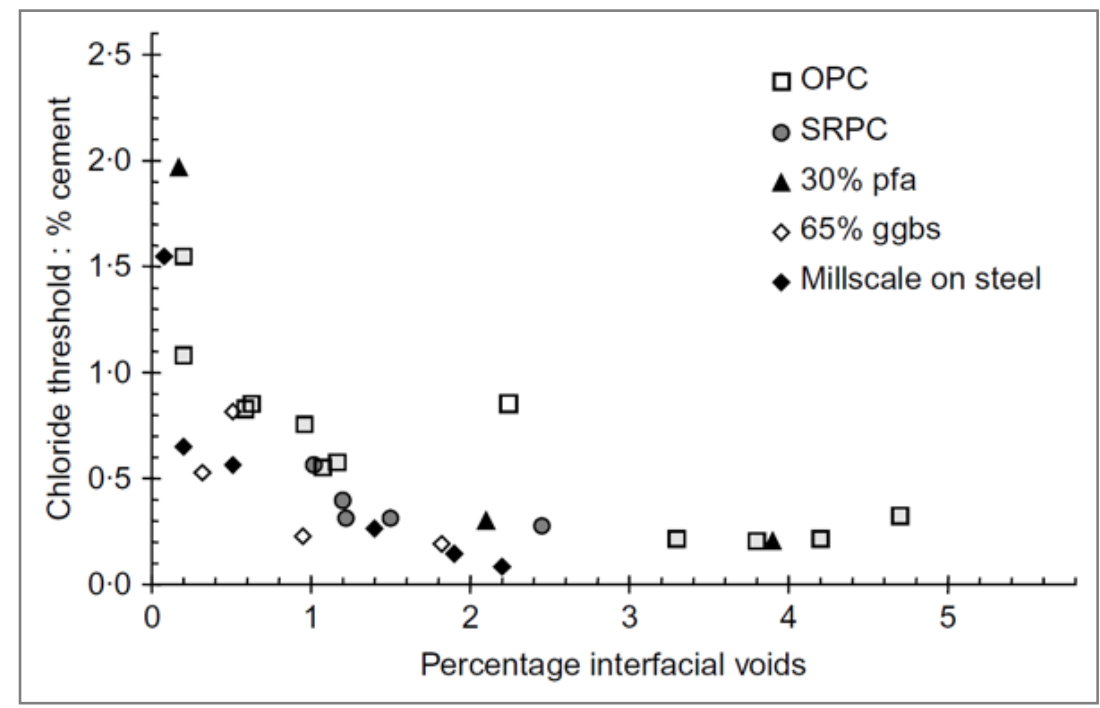

Fig. 6. Relationship between $C_{\text {crit }}$ and entrapped air void content at the SCI for a range of binder types and steel surface conditions $[83,88]$. Specimens were "saturated with water" and submerged in chloride solution during test.

However, there are a number of studies that have reported findings contrary to the above [10, 32, 90-92]. In $[10,32,90,91]$, specimens were exposed to wet/dry cycles in chloride solution and corrosion was detected by monitoring the corrosion potential of the steel. The specimens included lab-made reinforced concrete specimens (with ribbed steel) and cores drilled from various 20-50-year-old engineering structures. Upon corrosion initiation, the specimens were split and visually examined. Relatively large interfacial air voids of up to several $\mathrm{mm}$ in diameter were frequently found at the SCI, but the location of corrosion initiation, as evidenced by presence of deposited corrosion products, rarely coincided with the location of voids. Corrosion was found to initiate at macroscopic ( $>0.5 \mathrm{~mm}$ ) air voids in only $12 \%$ of the studied cases (Fig. 7) [32]. However, in these cases, $C_{\text {crit }}$ was generally higher than in cases where corrosion initiated elsewhere (Fig. 7). An important observation made in these studies is that in many cases corrosion was found to initiate at locations with no particular visual irregularities, despite the presence of air voids at the SCI elsewhere within the specimen.

In conclusion, the impact of interfacial air voids on corrosion initiation in concrete cannot be generalized. The frequently held view that air voids a priori promote corrosion initiation is not always true, based on the reviewed 
data. The role of interfacial air voids is probably influenced by other conditions, particularly the moisture conditions in the concrete (see section 3.6).

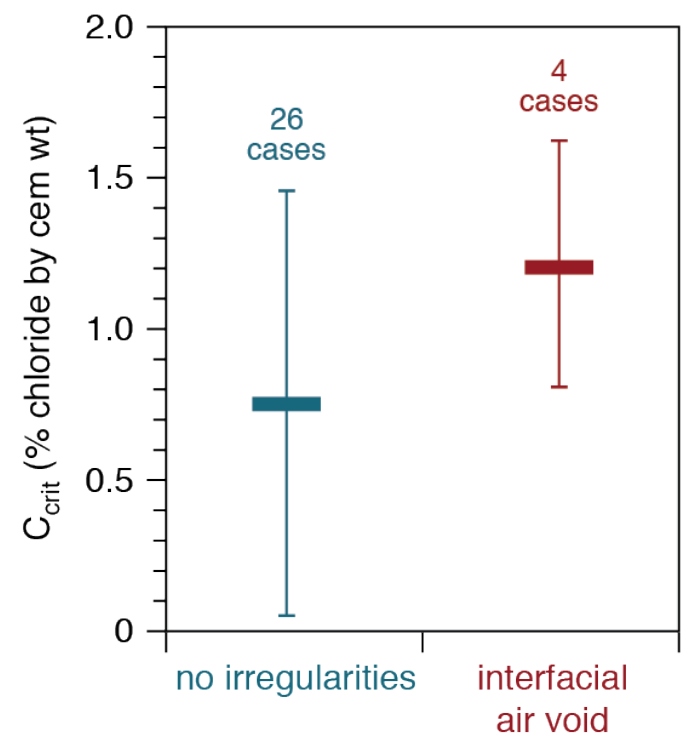

Fig. 7. $\mathrm{C}_{\text {crit }}$ observed in 30 samples taken from various engineering structures in Switzerland [32]. In the majority of samples (26 cases) visual inspection of the SCI upon splitting the specimens after corrosion initiation did not reveal any visually apparent irregularities at the SCI. Only in $\mathbf{4}$ cases did corrosion coincide with interfacial air voids. Symbol $=$ average, whisker $=$ standard deviation .

\subsubsection{Artificially created interfacial voids}

In various studies, artificial defects, supposedly representing interfacial voids, were introduced by means of

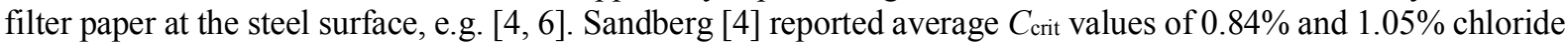
by cement mass in the presence and absence of filter paper defects, respectively, from field exposure (splash zone) (standard deviation in both cases approx. $0.23 \%$ chloride by cement mass; based on 8 replicate specimens). In submerged conditions and from laboratory tests, the impact of the filter paper was found to be lower and not statistically significant. Nygaard [6] examined reinforced mortar specimens containing artificial defects created by covering part of the rebar with a filter paper prior to casting. These specimens were continuously immersed in chloride solution and it was found that the chloride concentration needed to initiate corrosion decreased with increasing area fraction of the filter paper.

It must be noted, however, that filter paper is likely to behave differently than natural voids at the SCI. This is because filter paper typically has pores that are coarser than those of the cement paste, but much finer than those of macroscopic interfacial voids. Thus, introducing filter paper to simulate macroscopic interfacial voids may keep these artificially created voids in a higher moisture condition compared to the case of natural interfacial voids. Therefore, care needs to be taken when adopting the conclusions drawn from filter paper studies to evaluate the effect of interfacial air voids.

\subsubsection{Settlement and bleeding zones}

Fresh concrete reduces its volume in the formwork due to its own weight (compaction of matter, removal of entrapped air) and early chemical shrinkage. This volume reduction is called settlement, and may give rise to (empty) cracks/zones, among others, at the reinforcement. If the concrete is unstable or the setting time is long, settlement may be accompanied by segregation and bleeding. In case of bleeding, bleed water may accumulate under larger obstacles, e.g. under the reinforcement and - if present - in the initially empty settlement zones. During hydration the bleed water will be (partly) absorbed into the surrounding paste due to chemical shrinkage causing self-desiccation. Settlement and bleeding zones may thus be empty (air-filled) or partly water-filled. Unless exposed to highly moist environments, it is unlikely that water will be present in large quantities in settlement and bleeding zones in the hardened concrete due to the size of these voids. An exception to this is the case when cracks in the concrete cover provide a link from the settlement and bleeding zones to the exposure 
environment. The size of settlement and bleeding zones increase with the height of concrete below the reinforcing steel. As a result, top-cast horizontal bars exhibit more defects at the underside perimeter than bottom-cast horizontal bars. This effect is well-known by structural engineers as the "top-bar effect", which affects the bond properties. Settlement and bleeding zones were documented to occur particularly at the underside of horizontal rebars. This is important because depending on the orientation of the exposed concrete surface, chlorides may arrive to the steel from the underside or upper side [93]. For a more detailed review of the properties of settlement and bleeding zones, the reader is referred to [12].

A number of researchers found that settlement or bleeding zones may have an effect on corrosion [5, 9, 11, 44, $90,94,95]$, i.e. that corrosion occurred preferably on the underside of reinforcing steel bars, where settlement or bleeding zones exist. In most of these studies, the reported observations were made after considerable time had passed after corrosion initiation. The reported observations include visual inspection upon splitting the specimen such as determining the location of corrosion (e.g. on undersides of rebars) or the extent of the corroded steel area. However, these works do not permit quantifying the influence of settlement and bleeding zones on corrosion initiation of reinforced concrete, as the results may be influenced by the impact on corrosion propagation. Data on initiation is available from two laboratory studies $[90,95]$ that reported $C_{\text {crit }}$, distinguishing between initiation on the underside of rebars that were horizontally oriented during casting (presumably showing settlement or bleeding zones [96]) and initiation at vertically oriented rebars (presumably free of settlement or bleeding zones [96]), as summarized in Fig. 8. Moreover, the figure shows results [91, 97] from testing samples taken from two different engineering structures. While the literature is somewhat contradictory on the qualitative effect, overall, the influence of settlement or bleeding zones on $C_{\text {crit }}$ is modest, both increasing or depressing $C_{\text {crit }}$ by $40 \%$ at most (under the conditions of testing).

Although the data are limited, Fig. 8 indicates that the adverse impact of settlement and bleeding zones is slightly more pronounced on smooth rather than ribbed steel bars and in moisture states close to saturation (immersed) compared to lower moisture contents (wetting/drying).

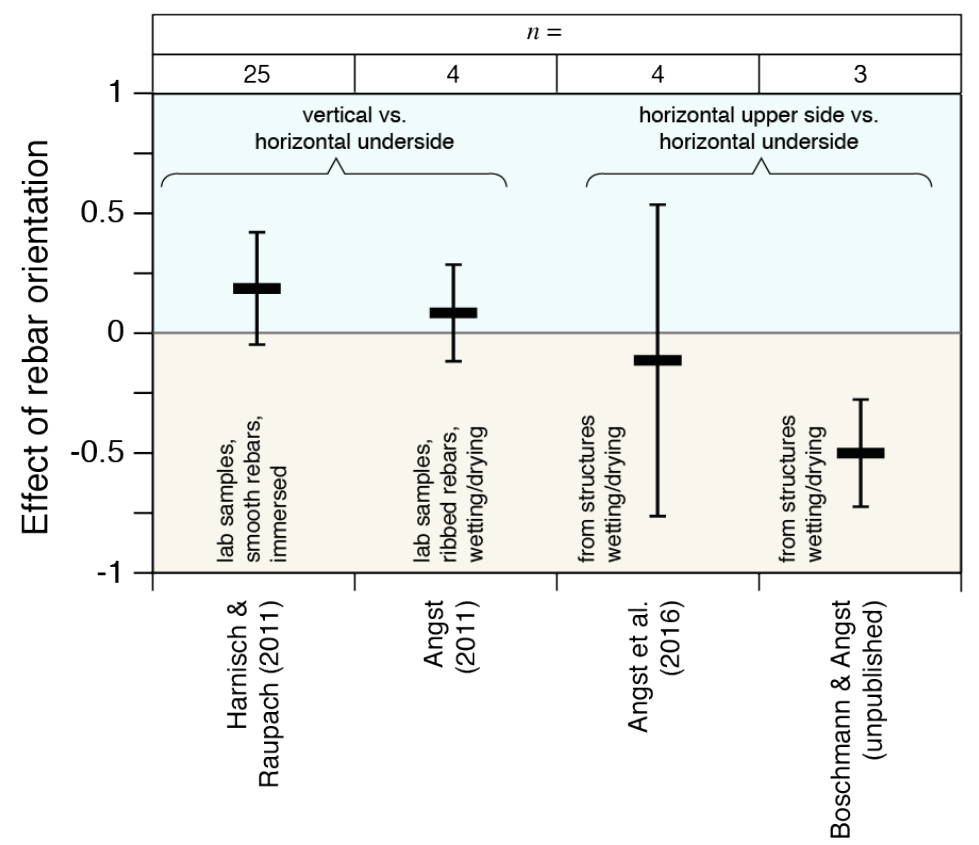

Fig. 8. Effect of rebar orientation on corrosion initiation $\left(C_{\text {crit }}\right)[90,91,95,97]$. Some data indicate that vertical rebars were less susceptible to corrosion initiation than horizontal bars, and others suggest the upper side of horizontal rebars exhibit a better resistance against corrosion initiation than the underside of horizontal rebars (reference case). The literature results are somewhat contradictory on the impact of settlement and bleeding zones.

\subsubsection{Cracks, slip, and separation (mechanical damage at the $\mathrm{SCl}$ )}

Cracking of the concrete may lead to formation of voids at the steel surface [12]. This happens both when cracks appear in early stages (e.g. plastic shrinkage cracks, temperature induced cracks) and due to mechanical loading of mature concrete. The morphology of cracks varies depending on the cause. Bending cracks are usually accompanied by slip and separation at the rebar. A main difference between other interfacial voids e.g. settlement zones and crack-related interfacial voids, is that cracks may extend through the entire concrete cover concrete and, thus, exposing the voids to the environment, while settlement zones are encapsulated in the concrete and, thus, 
typically have limited direct access to the exposure environment. This has significant consequences for exchange of moisture, oxygen, and ions with the exposure environment; the concentrations of these can dramatically and relatively quickly change in crack-related voids, while such changes are comparatively slow in settlement and bleed water zones. In structures under load, bending cracks could intercept top-cast tensile bars affected by the top-bar effect. In this case, cracks allow quick access of settlement zones to the exposure environment and pitting nucleation was reported to occur along the affected rebars and not only in zones close to the cracks [98].

The premature initiation of reinforcement corrosion due to the presence of cracks in the cover of concrete structures is well-known and has been investigated for more than 50 years, e.g. reviewed in [99-102]. Many investigations have generally concluded that cracking in the concrete cover facilitates rapid chloride ingress and subsequently reduces the time to corrosion initiation (e.g. [103]). The presence of cracks, interfacial slip and separation caused by mechanical loading has been reported to cause relatively excessive cross-sectional reductions after 1-2 months of ponding with 10\% chloride solution [104], and both laboratory studies [105-109] and in-situ observations [110-112] have noted an expedited corrosion initiation in cracked concrete compared to pristine concrete. In contrast to this, Zhang et al. observed that corrosion did not occur at all cracks in loaded beams exposed to salt spray [98].

While most studies focused on the role of cracks in accelerating moisture and ion transport through the concrete cover, very little is known about its actual effect on corrosion initiation. Studies indicated that defects at the SCI induced by mechanical cracking may also reduce $C_{\text {crit }}[94,113]$. Available observations on the preferred sites for pitting corrosion initiation are inconsistent. Pacheco [114] reported that in areas with separation between steel and concrete, the prominent sites for corrosion pitting nucleation are where the separation decreases. However, Michel et al. [104] and Pease [101] observed corrosion only in areas with larger separation.

\subsection{Other characteristics at the SCI}

\subsubsection{Spacers, tie wires, rebar intersections, and welding spots}

While the review in [12] showed that the presence of spacers, tie wires and the location where rebars intersect can present local inhomogeneities, particularly in terms of concrete porosity at the SCI, we could not identify any literature addressing the influence of this on steel corrosion initiation. The few studies reviewed in [12] generally looked into concrete transport properties, e.g. chloride ingress, but no tests regarding the corrosion behavior of the reinforcing steel were reported. In addition to concrete microstructural features, locations where rebars are welded present metallurgical inhomogeneities, due to the effect of the welding heat. Jang and Iwasaki [115] reported that welded zones on rebars were more active than the base metal and acted preferably as anodes. Stefanoni et al. [116] also showed experimentally that welding spots on welded meshes are more susceptible to chloride-induced corrosion in alkaline environments than the remaining areas of the rebars.

\subsection{Moisture content and temperature}

Only very few studies reported the influence of the concrete moisture state and the temperature on corrosion initiation. Both Pettersson [117] and Song et al. [118] reported $C_{\text {crit }}$ and observed a pessimum in the $\mathrm{RH}$ range 80 $95 \%$. Pettersson [117] conditioned concrete specimens at various levels of RH and in capillary saturated state and exposed them briefly to saturated sodium chloride solution at intervals of 1-2 months [119]. Corrosion was considered to have initiated when the corrosion current density increased sharply to more than $10 \mu \mathrm{A} / \mathrm{cm}^{2}$, which we consider a criterion that may have required a very high amount of chlorides to be achieved particularly in the lower RH range. Song et al. [118] exposed concrete specimens at different RH and in immersed state during a year. The criterion for corrosion initiation was a corrosion current density higher than $0.5 \mu \mathrm{A} / \mathrm{cm}^{2}$. The method used for introducing chlorides is unclear. Boschmann and Angst exposed concrete specimens to chloride solutions, where one series was continuously immersed and another series was exposed to daily wetting/drying cycles. The $\mathrm{RH}$ in the concrete was measured at the depth of the rebar and found to be $95 \pm 2.5 \%$ during the wetting/drying cycles. Corrosion initiation was detected by means of a drop in steel potential.

Evaluating these data according to the methodology presented in section 2.2 yields Fig. 9. While $\mathrm{RH}<65 \%$ may be of little practical relevance for chloride-induced corrosion, the figure indicates that the moisture condition has a pronounced effect in the range from RH 80\% to capillary saturation (grey and white symbols in Fig. 9). This effect becomes smaller between RH 95\% and capillary saturation (black symbols in Fig. 9).

Repeated wetting and drying appears to create more critical conditions with lower $C_{\text {crit }}$ than at constant moisture state [120-122]. This was apparent from the unpublished data by Boschmann and Angst where the mean $C_{\text {crit }}$ was approx. 50\% higher in continuously immersed condition compared to wetting/drying. In agreement with this, using 
custom-made corrosion cells developed by Arup and Sørensen [123] and exposing them to chloride by submersion, wetting and drying or in the field, Sandberg and Sørensen [122] observed that submersion generally resulted in higher $C_{\text {crit. }}$ They concluded that the results supported the earlier suggested $[124,125]$ hypothesis of moisture and temperature variations at the steel surface promoting corrosion initiation. Very high $C_{\text {crit }}$ are expected in concrete submerged for long periods [124].

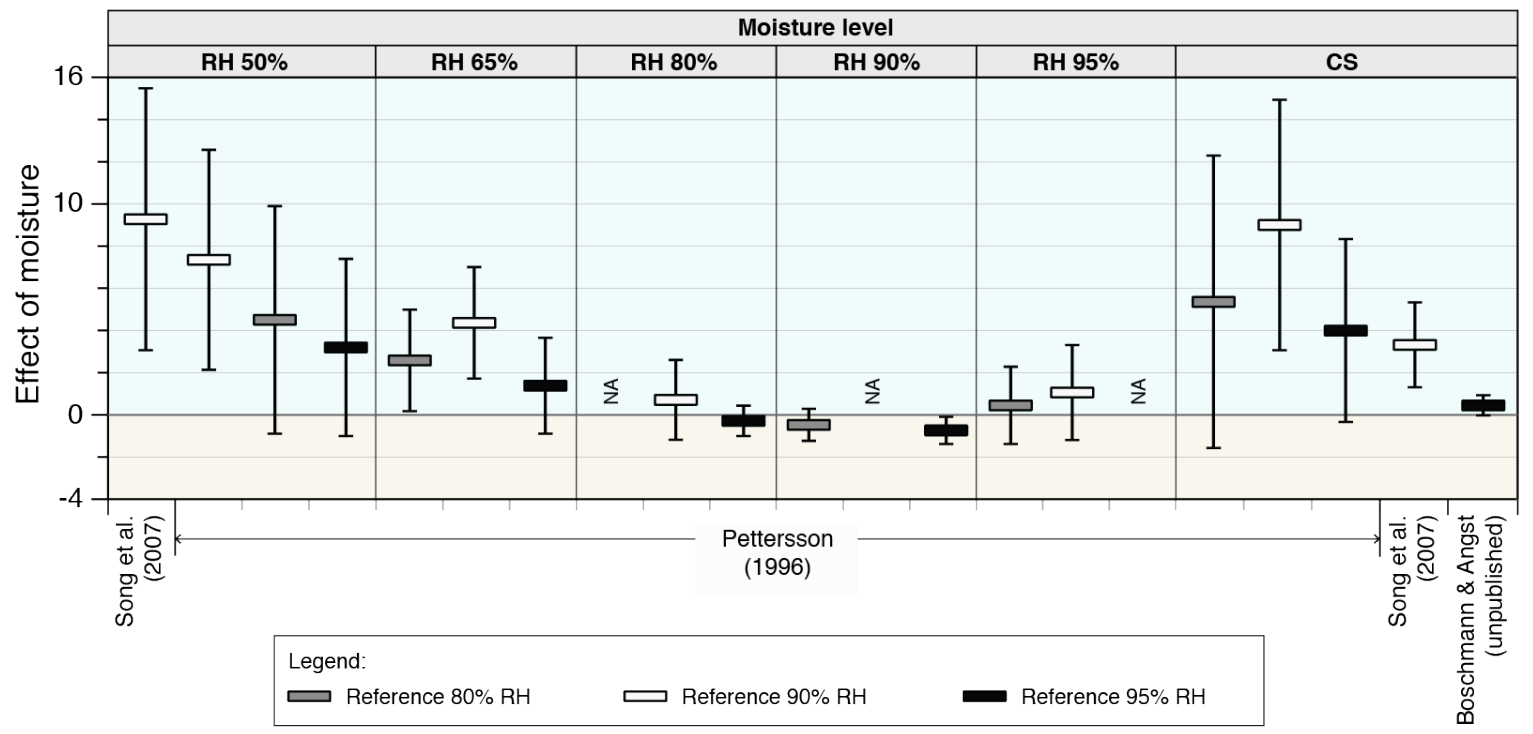

Fig. 9. Effect of concrete moisture state on corrosion initiation $\left(C_{\text {crit }}\right)$, based on Pettersson [117], Song et al. [118], and unpublished data by Boschmann $\&$ Angst, all reporting $C_{\text {crit }}$ as a function of the moisture state. $C S=$ capillary saturated. In both the work of Pettersson [117] and Song et al. [118] the number of replicate samples $(n)$ was not reported, Boschmann \& Angst studied 3 replicate samples. 


\section{Discussion}

\subsection{Dominating influencing factors}

Corrosion initiation in concrete is a stochastic process. Even when steel surface is in pristine condition and most confounding factors at the SCI that affect corrosion initiation are eliminated, corrosion may initiate at random sites on the steel surface when sufficient amount of chloride is present in the electrolyte. Where and how corrosion might initiate in these idealized conditions would depend mainly on the local imperfections of the passive film. Beyond this well-accepted stochastic nature of localized corrosion, the most significant factors affecting corrosion initiation of steel in concrete are related to the characteristics of the SCI, which are covered in this paper.

Fig. 10 summarizes the effects of the different local characteristics of the SCI according to the literature evaluated in this work. Note that due to the uncertainties in the data, as discussed in section 3, the focus of Fig. 10 lies on assessing the relative influences rather than a quantitative assessment of these effects on corrosion initiation. On this basis, we make the following striking observations:

- The degree to which steel is polished, the steel metallurgy, and the moisture content at the SCI are by far the most dominant influencing characteristics for chloride-induced corrosion initiation in concrete (among the characteristics for which we have sufficient data for a quantitative assessment). The effects of these characteristics are almost one order of magnitude higher than the effect of almost all the other characteristics of the SCI that were quantified. Further indication for the dominating effect of moisture content is apparent from results reviewed in the various cases of macroscopic interfacial concrete voids (section 4.2.2).

- We consider it of particular interest that factors such as cement type and w/b ratio, which are well-known to play major roles in concrete technology and concrete properties (e.g. strength, bulk transport properties, etc.), have comparatively small effects (Fig. 10).

- The different possible influencing factors have received highly unbalanced research attention. Cement type, $\mathrm{w} / \mathrm{b}$ ratio, and mill scale or rust layer influences have been studied most extensively. However, the effect on corrosion initiation of characteristics such as moisture, steel metallurgy, air voids, rebar geometry, spacers, etc. have been addressed in very few or no studies (note that here, we are not considering studies focusing on chloride transport through the cover).

- The best agreement on the effect of SCI characteristics described in the literature was found for mill scale and rust layers, passive film ageing, and moisture. Mixed conclusions were reported for the effects of w/b ratio, cement type as well as certain interfacial voids, but the studies generally agreed that the effect is relatively moderate for these characteristics.

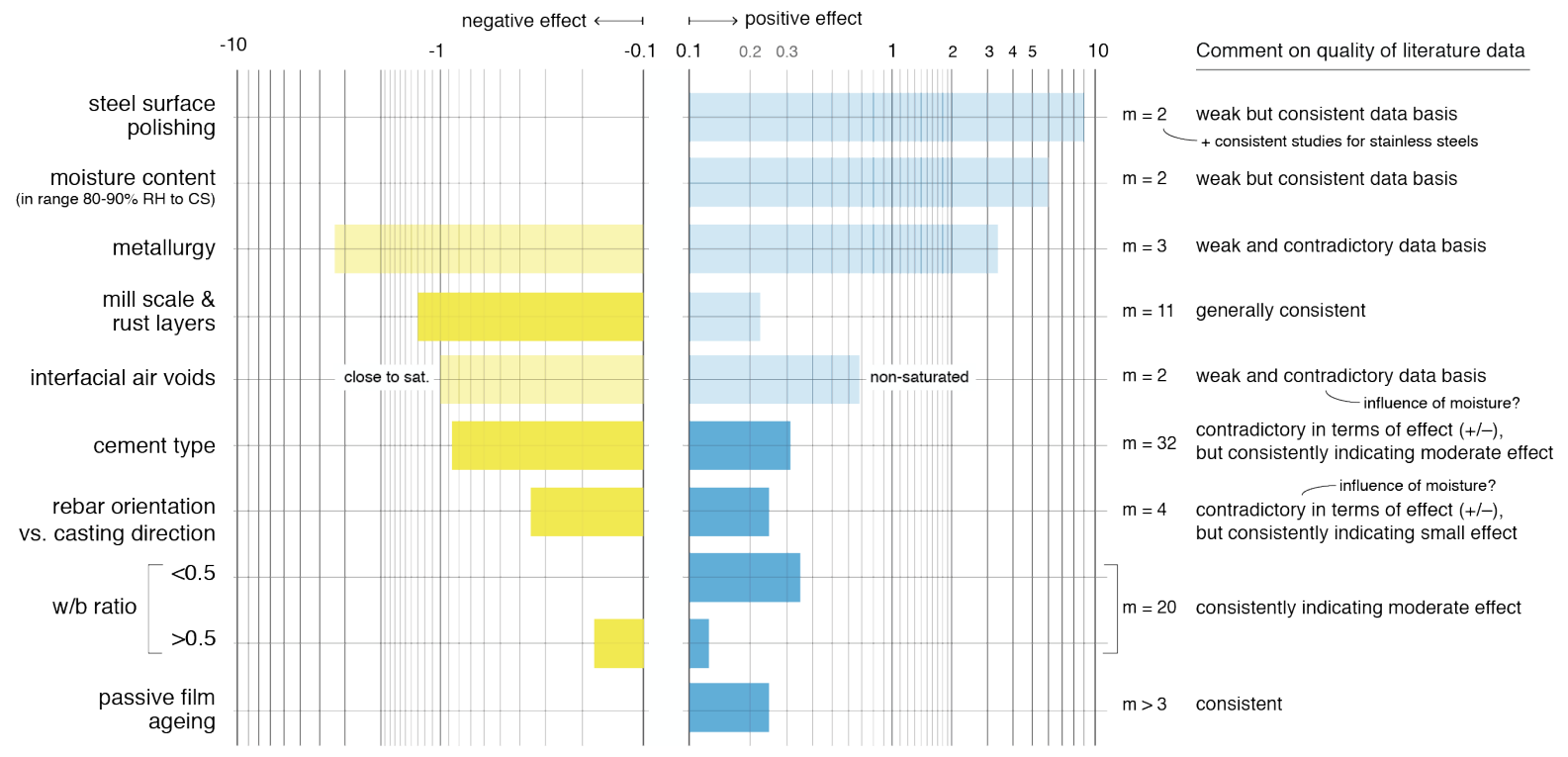

cracks, slip, separation; rebar geometry; spacers; tie wires; rebar intersections; welding spots; temperature $-m \approx 0 \quad$ no or insufficient data basis

Fig. 10. Compilation of the influencing factors evaluated in this work and their effects quantified according to the methodology described in section 2.2. The blue and yellow bars show the average of positive effects and the average of negative effects, respectively. Light bar colors indicate a low number of reviewed studies $(m)$. Note the logarithmic axis. 


\subsection{Hypotheses of working mechanisms}

\subsubsection{Steel metallurgy and surface condition}

Section 3.1 presented the effect of various characteristics related to the steel side of the SCI on corrosion initiation. A number of hypotheses have been proposed, that may be classified as follows:

- Crevice corrosion mechanism: Ghods et al. [41] suggested that cracks in the mill scale provide access for the concrete pore solution to reach the steel surface. Numerical simulations supported the hypothesis that the chemical composition of the pore solution within these cracks differs from that of the bulk solution through a process similar to the suggested mechanism of typical crevice corrosion [126]. This may lead to conditions favoring depassivation of the steel at the crack tip. It may be noted that crevices and cracks in the oxide scales may likely be of over-capillary dimensions and thus the hypotheses presented in section 4.2.2 may also apply to these. Similarly to the reasoning related to cracked oxides, it has been suggested that a rough surface, exhibiting depressions in the metal surface, provides a geometrical configuration in which diffusional transport limitations can more easily produce a sufficiently aggressive anolyte to sustain further local pit growth [127].

- Cathode effect sustaining early pit growth: Several authors suggested that the presence of oxides may provide an additional oxidation/reduction couple (Fe(II)/Fe(III)) that can - at least for a limited time - enhance the cathodic current capacity by a factor of $2-5[128,129]$. The higher cathodic current was also explained by different effective steel surface areas between clean and mill-scale surfaces. More effective cathodes in the vicinity of pit nucleation sites are likely to sustain early stage pit stabilization and pit growth, hence initiation of stable corrosion.

- Inhibited passivation: Li and Sagüés [34] suggested that in the absence of pre-existing oxides, a fresh, dense passive film can grow better on the steel surface than in the presence of oxides. Similarly, from results using potentiodynamic polarization (PDP) and electrochemical impedance spectroscopy (EIS) it was in [7,8] concluded that the mill scale can inhibit the formation of a passive film on steel exposed to alkaline solutions or mortar.

- Surface heterogeneity and size effect: A general explanation can be found in the inhomogeneity of the surface [36], e.g. in terms of chemical composition of the different surface components. Local electrochemical studies have revealed the marked diversity in local electrochemical behavior of as-received surfaces as well as their mutual polarization when immersed in an electrolyte [31,130]. Surface inhomogeneities have also been related to a size effect, meaning that larger exposed electrodes exhibit a higher probability of corrosion through a size effect $[10,127,131,132]$. Since surface roughness is related to the effective area, the size effect has been used to explain the influence of surface roughness on corrosion initiation [127].

While the data reviewed in this work appear to suggest a strong influence of steel metallurgy (Fig. 10), no conclusive hypotheses are currently available to explain this.

\subsubsection{Macroscopic interfacial concrete voids (MICV) and the importance of moisture state}

Section 0 presented the effect of various macroscopic interfacial concrete voids (MICV) on corrosion initiation. It became repeatedly apparent that their role in corrosion initiation is significantly affected by moisture state, which was furthermore supported by the marked overall effect of moisture (Fig. 10). Here, we attempt to provide hypotheses that are generally valid for the different macroscopic concrete voids. These include entrapped and entrained air voids, settlement and bleeding zones, and perhaps cracks, slip, and separation as well as other voids, e.g. at intersecting rebars or at spacer/rebar or stirrup/rebar interfaces, for which no literature documenting their influence on corrosion initiation is available. An important common feature of these MICVs is that their dimensions are above the capillary range. However, they differ in geometry and initial moisture condition as well as possible access to the exterior (Table 1), which will affect the availability of reactants and the efficiency of the electrical circuit in the corrosion cell [133].

Additionally, an important feature may be whether or not the MICVs exhibit a thin layer of cement hydration products coating the steel surface adjacent to the void. Such a layer is expected in all cases where the steel is initially embedded in concrete during casting, that is, before the formation of the MICV such as in bleeding and settlement zones, concrete cracks, slip, separation, and entrapped/entrained air voids. However, there are situations where such a cementitious layer is absent, e.g. an air bubble that is attached to the reinforcement from the very beginning and remained stationary during concrete casting and hardening. This may include entrapped air voids as well as gaps and crevices between intersecting rebars or between rebars and spacers [12]. 
Table 1. Geometry, moisture state, and access from exposure environment in different macroscopic interfacial concrete voids (MICVs)

\begin{tabular}{|c|c|c|c|c|c|}
\hline & $\begin{array}{l}\text { Entrained air } \\
\text { voids }\end{array}$ & $\begin{array}{l}\text { Entrapped air } \\
\text { voids }\end{array}$ & $\begin{array}{l}\text { Settlement } \\
\text { zones }\end{array}$ & Bleeding zones & $\begin{array}{l}\text { Cracks, slip } \\
\text { and } \\
\text { separation }\end{array}$ \\
\hline $\begin{array}{l}\text { Length scale, } \\
\text { perpendicular to } \\
\text { steel }\end{array}$ & $\mu \mathrm{m}-\mathrm{mm}$ & $\mu \mathrm{m}-\mathrm{cm}$ & $\mu \mathrm{m}-\mathrm{mm}$ & $\mu \mathrm{m}-\mathrm{mm}$ & $\mu \mathrm{m}-\mathrm{mm}$ \\
\hline $\begin{array}{l}\text { Length scale, } \\
\text { along steel }\end{array}$ & $\mu \mathrm{m}-\mathrm{mm}$ & $\mu \mathrm{m}-\mathrm{cm}$ & $\mathrm{cm}-\mathrm{m}$ & $\mathrm{cm}-\mathrm{m}$ & $\mu \mathrm{m}-\mathrm{cm}$ \\
\hline $\begin{array}{l}\text { Initially water } \\
\text { saturated }\end{array}$ & No & No & No & Yes & $\begin{array}{l}\text { Depends on } \\
\text { exposure }\end{array}$ \\
\hline $\begin{array}{l}\text { Access to } \\
\text { exterior } \\
\text { (exposure } \\
\text { environment) }\end{array}$ & $\begin{array}{l}\text { No, unless } \\
\text { linked to } \\
\text { exterior through } \\
\text { cracks in the } \\
\text { cover }\end{array}$ & $\begin{array}{l}\text { No, unless } \\
\text { linked to exterior } \\
\text { through cracks } \\
\text { in the cover }\end{array}$ & $\begin{array}{l}\text { No, unless linked } \\
\text { to exterior } \\
\text { through cracks in } \\
\text { the cover }\end{array}$ & $\begin{array}{l}\text { No, unless } \\
\text { linked to } \\
\text { exterior } \\
\text { through cracks } \\
\text { in the cover }\end{array}$ & Yes \\
\hline
\end{tabular}

Our hypothesis on the combined impact of moisture state and macroscopic interfacial concrete voids on corrosion initiation is illustrated in Fig. 11. In completely saturated state, steel is directly exposed to liquid water (containing chlorides [134]) within the void (Fig. 11a). In this case, the steel will be more prone to corrosion initiation than steel covered with cement paste. This is because of the absence of calcium hydroxide at the steel surface that locally buffers the $\mathrm{pH}$ during stages of early pitting corrosion. During this stage the competitive migration of chloride and hydroxyl ions towards the anodic site is decisive for establishing stable pit growth [135, 136]. Thus, a locally lowered $\mathrm{pH}$ buffer capacity significantly impairs the corrosion inhibiting mechanism associated with the presence of a calcium hydroxide rich layer at the SCI, as postulated in [1,2].

In partially saturated MICVs, i.e. voids containing both liquid electrolyte and air (Fig. 11b), there is, in addition to the susceptibility to corrosion in the wet areas as mentioned above, an increased availability of oxygen from the air-filled part that potentially aggravates the corrosion initiation process. The mechanism for this may be related to, on the one hand, generally raising the steel potential prior to pitting nucleation $[55,56]$ and, on the other hand, enhancing the supply of oxygen to sustain the cathodic activity that is needed to overcome the stage of early pit growth and to achieve stable pitting corrosion [136-138]. Thus, steel in contact with partially saturated MICVs may be considered the worst case.

Fig. 11c shows an air-filled (non-saturated, "dry”) MICV. Here, supply of oxygen through diffusional transport across the film of adsorbed water at the steel surface is high. On the contrary, ionic transport within the film of adsorbed water is expected to be severely limited [139]. Thus, it is unlikely to achieve pitting corrosion in the parts of the steel covered with adsorbed water, as this requires the formation of significant galvanic elements, which is impossible due to the strong ohmic control within the adsorbed water film. Electrical resistance measurements reported in [133] indicated that interfacial air voids at non-saturated conditions are indeed electrically (and electrochemically) inactive. However, for the reasons given in the previous paragraph, air-filled MICVs may promote corrosion initiation in cement-paste covered steel areas close to the MICVs, as indicated by the red cross in Fig. 11c.

Fig. 11d shows the case where a cement paste layer is present at the steel surface adjacent to the MICV. Here, the susceptibility to corrosion is expected to be lower than in the case of Fig. 11b, mainly due to the pH buffering and barrier effect of the cement paste layer. Depending on the thickness of this cementitious layer as well as the reservoir of calcium hydroxide available, corrosion may still preferentially start here, particularly in unsaturated condition due to the combination of increased supply of oxygen and high ionic conductivity enabling the formation of galvanic elements to stabilize early pit growth.

Summarizing the different cases illustrated in Fig. 11, corrosion may be expected to initiate in the MICV or next to it, depending on the saturation state. The location of corrosion initiation with respect to the location of MICVs was not always evidenced with full clarity from studies reporting visual inspections of rust at the SCI. This may also have been masked to some extent by the fact that increased oxygen concentrations close to and in voids may locally favor precipitation of corrosion products that diffuse towards voids from other, more deoxygenated locations (Fig. 11c).

The strong dependency of corrosion initiation on the moisture state of interfacial air voids could explain the seemingly inconsistent findings from different studies (cf. section 3.4.1). Entrapped air voids initially contain no 
moisture and if they remain dry, corrosion would not occur at these locations due to the lack of electrolyte to support initiation. In the work of Angst et al. [10, 32, 90, 91], MICVs were clearly not saturated [12] owing to the cyclic wet/dry exposure conditions applied. Thus, it is not surprising that they were rarely found to be preferential sites for corrosion initiation. In other studies [83, 85, 87, 88], however, concrete specimens were closer to saturation due to being continuously submerged, and potential partial saturation of the MICVs could explain the observation of corrosion initiation close to or at air voids.

Concerning the local role of oxygen as above hypothesized for Figs. 11c-d, it may be mentioned that often a locally triggered anode is galvanically coupled with the rest of the reinforcing steel bar. Thus, unless the concrete electrical resistivity is extremely high, the local presence of oxygen may lead to more global rather than pronounced local differences in steel potential on the rebar surface. Hence, the cathodic current can be supplied from the comparatively large rebar surface and not critically depend on a local supply of oxygen. This may thus be another explanation for the experimental observations where corrosion was not found to preferentially occur at MICVs. Global effects on the value of $C_{\text {crit }}$ as a result of long distance macrocell coupling have been documented for submerged structures $[140,141]$, and interpreted as resulting from the dependence of $C_{\text {crit }}$ on steel potential mentioned earlier $[55,56]$.

a)

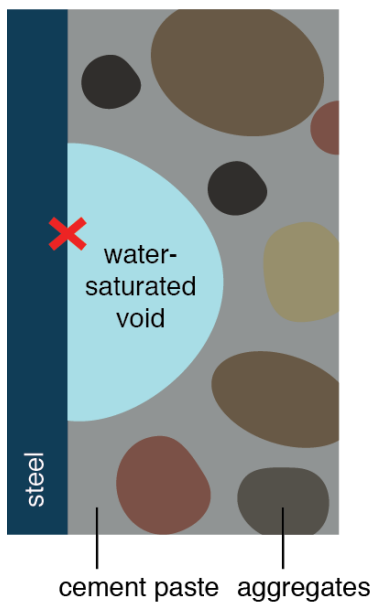

b)

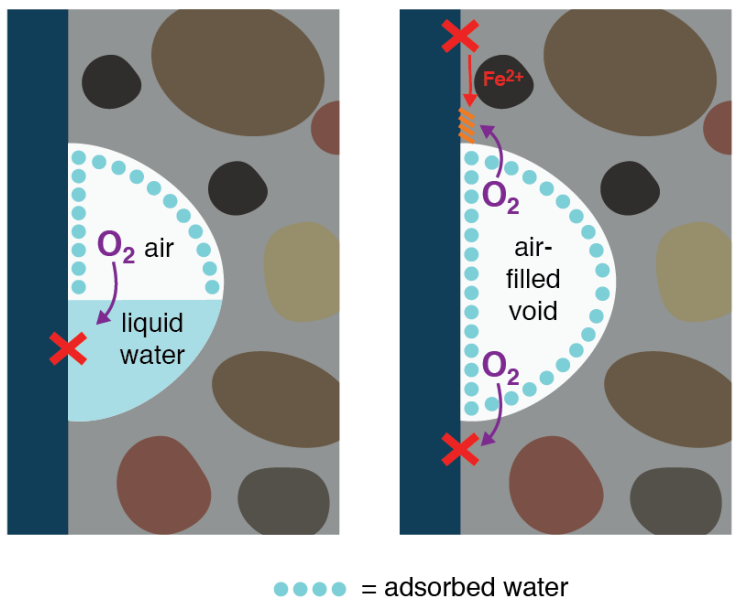

d)

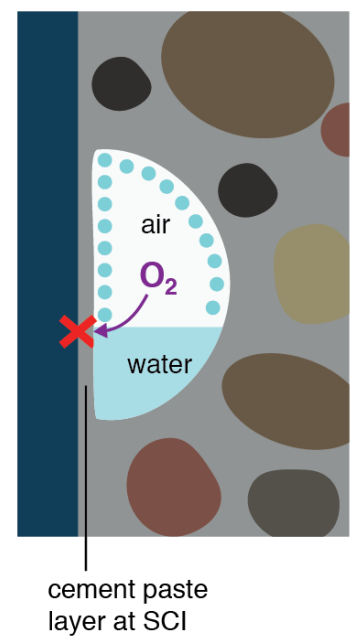

Fig. 11. Schematic sketches illustrating possible roles of macroscopic interfacial concrete voids (MICV) in corrosion initiation. Here, we use the example of an air void, but the same processes may occur in other MICVs. The red crosses indicate the location of corrosion initiation. a) water-saturated MICV with limited $\mathrm{pH}$ buffered liquid due to the relatively long diffusion path for hydroxyl ions released by $\mathrm{CH}$; b) partially saturated MICV promoting corrosion in the liquid part, amongst other reasons due to the oxygen supply from the air-filled part; c) non-saturated (air-filled)

void acting as oxygen reservoir for nearby zones, either promoting corrosion initiation (red cross shown at the bottom) or precipitation of corrosion products diffusing towards the void from an initiation site elsewhere (red cross shown at the top). Finally, d) illustrates a case where the steel adjacent to the void is coated with a thin cement paste layer, where moisture, oxygen, and a $\mathrm{pH}$ buffer $\left((\mathrm{CaOH})_{2}\right)$ may be abundant at the steel surface to influence corrosion initiation.

In engineering practice, fully saturated MICVs are considered unlikely to be present in uncracked concrete, as even in submerged conditions it can a take very long time to fill pores in the over-capillary range [12]. The proposed mechanism leading to saturation is that dissolution of the air (held in a void) into the surrounding pore water leads to a gradual filling of the void with liquid water [142]. The process is estimated to be very slow [142], and thus MICVs may not be completely filled during the lifetime of a structure. However, depending on the moisture exposure, MICVs may be partially water-filled. Finally, it should be mentioned that in cracked concrete where the cracks provide a direct path between MICV and the exposure environment, saturation of MICV may be reached relatively fast.

The microstructure and the chemical composition of the binder as well as the geometric configuration (e.g. cover, SCI characteristics) and temperature affect the actual moisture content and the pore liquid composition at the steel surface. However, numerical simulations performed by Ryu et al. [143] indicated that short-term drying and wetting have little effect on the internal moisture content in uncracked concrete. Variations in the range of 15$35^{\circ} \mathrm{C}$ and $30-90 \% \mathrm{RH}$ were found to affect moisture content in concrete with $\mathrm{w} / \mathrm{b}=0.3$ and 0.6 to depths of 10 and $30 \mathrm{~mm}$, respectively. For continuous rainfall during $24 \mathrm{~h}$, the predicted moisture change in $\mathrm{w} / \mathrm{b}=0.6$ concrete was evident to a depth of $30 \mathrm{~mm}$. The moisture content at depths $\geq 50 \mathrm{~mm}$ from the surface was scarcely affected [143]. Using recorded meteorological data for simulating internal temperature and moisture conditions in a concrete, 
Flint at al. [144] found, for concrete $(\mathrm{w} / \mathrm{b}=0.5)$ in northern climate (Lofoten, Norway), that the temperature change was "instantaneous" throughout the investigated depth of $50 \mathrm{~mm}$, whereas the degree of saturation was significantly affected only in the outermost 20-30 mm. Relling [145] measured convection zones (zones with varying moisture state) in Norwegian marine bridges of approximately $10 \mathrm{~mm}$. Similar results were also reported by Moro, based on monitoring of exposed concrete with sensors [146].

In summary, it can be expected that engineering structures in chloride-bearing environments are typically exposed to moistures in the range from $80 \% \mathrm{RH}$ to direct contact with liquid water (splash, tidal and submerged zones). Depending on exposure and cover depth, the moisture state in macroscopic (over-capillary) interfacial concrete voids discussed here can vary considerably, which in turn plays a major role on the effect of these voids on corrosion initiation in concrete.

\subsubsection{Cement type and $w / b$ ratio}

Perhaps one of the more striking findings of this review is that the cement type and the $\mathrm{w} / \mathrm{b}$ ratio, both being important parameters in concrete technology and durability design, have relatively small effects on corrosion initiation. Without doubt, these parameters will continue to be important in ensuring the durability of concrete structures. However, their primary role appears to be in controlling mass transport through the concrete cover. Their role in affecting the susceptibility of steel embedded in cementitious matrix to corrosion seems secondary.

Nevertheless, there are a number of hypotheses about how cement type and w/b may influence initiation of chloride-induced corrosion. Due to the observed moderate effect (Fig. 10), we decided to present here only a summary of these hypotheses and refer to the literature for more details. The cement type affects the pore solution composition, particularly $\mathrm{pH}$ and its buffer capacity, and the microstructure [147-150]. Moreover, SCMs can affect chloride binding capacity $[148,151]$. Finally, cement type and w/b ratio have an influence on the stability and packing of particles and thus on the micro- and macrostructure at the SCI such as the morphology and width of settlement and bleeding zones [96].

\section{Conclusions}

This review of the literature on initiation of chloride-induced corrosion of steel in concrete has revealed that parameters well-known to be important in concrete technology - such as w/b ratio and cement type (at least PCSCM blends) - have relatively small influences on the actual corrosion susceptibility of steel embedded in a cementitious matrix. Future scientific and engineering developments towards predicting corrosion initiation in concrete would benefit from considering other parameters, namely steel properties - including metallurgy, presence of mill scale or rust layers, and surface roughness - as well as the content and spatial distribution of moisture in microscopic and macroscopic voids at the SCI. Although limited data are available in the literature, our review suggests that these characteristics of the SCI have a strong influence on the susceptibility to corrosion. Thus, we expect that considering these factors will improve the reliability of future predictive models for corrosion initiation in concrete.

Our findings imply that endeavors to develop experimental methods aiming at determining $C_{\text {crit }}$ as a function of concrete mix proportions - utilizing standardized steel surfaces and concrete compaction methods - may have little relevance in holistically assessing the corrosion performance of reinforced concrete structures.

Although w/b ratio and cement type seem to have a surprisingly small effect on the corrosion susceptibility, these parameters will continue to play an important role in service life modeling, durability design, and condition assessment, since they have a strong impact on bulk concrete transport properties and on concrete cracking, and thus on the transport of chloride, moisture, oxygen, and carbon dioxide through the concrete cover, as well as on the propagation of corrosion.

We recommend that further studies focus on those characteristics that have so far received the least research attention or where the literature is inconclusive, but indicate potentially dominant effects. These include the moisture conditions at the SCI, interfacial air voids, reinforcing steel properties including metallurgy as well as macroscopic and microscopic geometry of the rebar and its surface, spacers, rebar intersection, welding points, and mechanical damage (cracks, slip, separation). On the contrary, parameters such as w/b ratio, cement type (with the exception of alkali-activated cements and other novel cements), and steel passivity may not need the highest priority in future studies related to the corrosion susceptibility of steel embedded in a cementitious matrix because literature have consistently indicated merely moderate effects.

A final comment should be made on the quality of the available literature data. In the course of reviewing the extensive number of scientific publications, we found that important experimental details (such as the method of saturating concrete or introducing chlorides, or the number of replicate specimens used) were often not reported, which significantly impeded the interpretation of the data. We consider it unsatisfactory that, after more than half 
a century of research on the issue of steel corrosion in concrete, many questions remain open, partly due to a simple lack of adequate reporting.

\section{Acknowledgements}

We acknowledge the input provided by all TC members attending the discussions of the TC meetings on 22 October 2017 (Philadelphia, U.S.), 7 April 2017 (Paris, France), 14 September 2017 (Zurich, Switzerland), 14 October 2017 (Anaheim, U.S.), 27 March 2018 (Sheffield, UK), 28 August 2018 (Delft, the Netherlands), 21 February 2019 (Zurich, Switzerland), and 19 March 2019 (Rovinj, Croatia). Additionally, we acknowledge the so far unpublished results that were provided by Raoul François from Université de Toulouse, France, (Fig. 5), and by Carolina Boschmann from ETH Zurich, Switzerland, (Figs. 8 and 9).

\section{Compliance with ethical standards}

\section{Conflict of interest}

The authors declare that they have no conflict of interest.

\section{References}

1. A. Bäumel (1959) Die Auswirkung von Betonzusatzmitteln auf das Korrosionsverhalten von Stahl in Beton. Zement-Kalk-Gips 7:294-305

2. C. L. Page (1975) Mechanism of corrosion protection in reinforced concrete marine structures. Nature 258:514-515

3. T. Yonezawa, V. Ashworth and R. P. M. Procter (1988) Pore solution composition and chloride effects on the corrosion of steel in concrete. Corrosion 44(7):489-499

4. P. Sandberg (1998) The effect of defects at the steel-concrete interface, exposure regime and cement type on pitting corrosion in concrete. Report TVBM-3081. Lund University, Sweden.

5. T. A. Soylev and R. François (2003) Quality of steel-concrete interface and corrosion of reinforcing steel. Cem. Concr. Res. 33(9):1407-1415

6. P. V. Nygaard (2003) Effect of Steel-Concrete Interface Defects on the Chloride Threshold for Reinforcement Corrosion. MSc thesis. Danish Technical University (DTU)

7. C. L. Page (2009) Initiation of chloride-induced corrosion of steel in concrete: role of the interfacial zone. Mater. Corros. 60(8):586-592

8. U. Angst, A. Rønnquist, B. Elsener, C. K. Larsen and Ø. Vennesland (2011) Probabilistic considerations on the effect of specimen size on the critical chloride content in reinforced concrete. Corros. Sci. 53:177-187

9. R. J. Zhang, A. Castel and R. François (2011) Influence of steel-concrete interface defects owing to the topbar effect on the chloride-induced corrosion of reinforcement. Mag Concrete Res 63(10):773-781

10. U. M. Angst and B. Elsener (2017) The size effect in corrosion greatly influences the predicted life span of concrete infrastructures. Sci Adv 3(8)

11. J. J. Shi and J. Ming (2017) Influence of defects at the steel-mortar interface on the corrosion behavior of steel. Constr Build Mater 136:118-125

12. U. M. Angst, M. R. Geiker, A. Michel, C. Gehlen, H. Wong, O. B. Isgor, B. Elsener, C. M. Hansson, R. Francois, K. Hornbostel, R. Polder, M. C. Alonso, M. Sanchez, M. J. Correia, M. Criado, A. Sagues and N. Buenfeld (2017) The steel-concrete interface. Mater Struct 50(2):143

13. U. Angst, B. Elsener, C. K. Larsen and Ø. Vennesland (2009) Critical chloride content in reinforced concrete - A review. Cem. Concr. Res. 39:1122-1138

14. Y. Cao, C. Gehlen, U. Angst, L. Wang, Z. D. Wang and Y. Yao (2019) Critical chloride content in reinforced concrete - An updated review considering Chinese experience. Cement Concrete Res 117:58-68

15. A. Stuart and J. K. Ord (1998) Kendall's Advanced Theory of Statistics. John Wiley \& Sons,

16. L. Tang, J. M. Frederiksen, U. M. Angst, R. Polder, M. C. Alonso, B. Elsener, R. D. Hooton and J. Pacheco (2018) Experiences from RILEM TC 235-CTC in recommending a test method for chloride threshold values in concrete. RILEM TECHN LETT 3:25-31

17. G. Rehm and D. Russwurm (1977) Assessment of concrete reinforcing bars by the Tempcore process. Betonwek + Fertigteil-Technik 6:300-307 
18. A. Ray, D. Mukerjee, S. K. Sen, A. Bhattacharya, S. K. Dhua, M. S. Prasad, N. Banerjee, A. M. Popli and A. K. Sahu (1997) Microstructure and properties of thermomechanically strengthened reinforcement bars: a comparative assessment of plain-carbon and low-alloy steel grades. J. Mater. Eng. Perform. 6(3):335-343

19. D. A. Lopez, T. Perez and S. N. Simison (2003) The influence of microstructure and chemical composition of carbon and low alloy steels in CO2 corrosion. A state-of-the-art appraisal. Mater Design 24(8):561-575

20. P. P. Sarkar, P. Kumar, M. K. Manna and P. C. Chakraborti (2005) Microstructural influence on the electrochemical corrosion behaviour of dual-phase steels in 3.5\% NaCl solution. Mater Lett 59(1920):2488-2491

21. G. Wranglen (1974) Pitting and sulphide inclusions in steel. Corros. Sci. 14(5):331-349

22. D. Trejo and R. G. Pillai (2003) Accelerated chloride threshold testing: Part I - ASTM A 615 and A 706 reinforcement. ACI Mater. J. 100(6):519-527

23. D. Trejo and R. G. Pillai (2004) Accelerated chloride threshold testing - Part II: Corrosion-resistant reinforcement. ACI Mater. J. 101(1):57-64

24. U. Angst and B. Elsener (2015) Forecasting chloride-induced reinforcement corrosion in concrete - effect of realistic reinforcement steel surface conditions, Proc. International Conference on Concrete Repair, Rehabilitation and Retrofitting (ICCRRR), Leipzig, Germany,

25. S. A. O. Kumar (2017) Microstructural and corrosion characteristics of quenched and self-tempered (QST) steel reinforcing bars. M.S. Thesis

26. D. Trejo, P. J. M. Monteiro, B. C. Gerwick and G. Thomas (2000) Microstructural design of concrete reinforcing bars for improved corrosion performance. Aci Mater J 97(1):78-83

27. O. Kelestemur, M. Aksoy and S. Yildiz (2009) Corrosion behavior of tempered dual-phase steel embedded in concrete. Int J Min Met Mater 16(1):43-50

28. O. Kelestemur and S. Yildiz (2009) Effect of various dual-phase heat treatments on the corrosion behavior of reinforcing steel used in the reinforced concrete structures. Constr Build Mater 23(1):78-84

29. C. Alonso, C. Andrade, M. Castellote and P. Castro (2000) Chloride threshold values to depassivate reinforcing bars embedded in a standardized OPC mortar. Cem. Concr. Res. 30:1047-1055

30. I. Zafar and T. Sugiyama (2014) Laboratory investigation to study the corrosion initiation of rebars in fly ash concrete. Mag Concrete Res 66(20):1051-1064

31. L. Michel and U. M. Angst (2018) Towards understanding corrosion initiation in concrete - Influence of local electrochemical properties of reinforcing steel, Proc. 5th Int. Conf. Concrete Repair, Rehabilitation and Retrofitting - ICCRRR, 2018, Cape Town, South Africa,

32. C. Boschmann Käthler, U. M. Angst and B. Elsener (2018) Towards understanding corrosion initiation in concrete - influence of local concrete properties in the steel-concrete interfacial zone, Proc. 5th Int. Conf. Concrete Repair, Rehabilitation and Retrofitting - ICCRRR, 2018, Cape Town, South Africa,

33. L. T. Mammoliti, L. C. Brown, C. M. Hansson and B. B. Hope (1996) The influence of surface finish of reinforcing steel and $\mathrm{pH}$ of the test solution on the chloride threshold concentration for corrosion initiation in synthetic pore solutions. Cem Concr Res 26(4):545-550

34. L. Li and A. A. Sagüés (2001) Chloride corrosion threshold of reinforcing steel in alkaline solutions Open-circuit immersion tests. Corrosion 57:19-28

35. P. Ghods, O. B. Isgor, G. A. Mcrae and G. P. Cu (2010) Electrochemical investigation of chloride-induced depassivation of black steel rebar under simulated service conditions. Corros Sci 52(5):1649-1659

36. D. Boubitsas and L. Tang (2015) The influence of reinforcement steel surface condition on initiation of chloride induced corrosion. Mater Struct 48(8):2641-2658

37. T. U. Mohammed and H. Hamada (2006) Corrosion of steel bars in concrete with various steel surface conditions. 103(4):233-242

38. S.-m. CHEN, B. CAO and K. MA (2014) Effects of pH-value and chloride ion concentration on passivation behavior of steel rebar in different surface conditions. Corrosion and Protection 35(8):808-812

39. E. Mahallati and M. Saremi (2006) An assessment on the mill scale effects on the electrochemical characteristics of steel bars in concrete under DC-polarization. 36(7):1324-1329

40. R. G. Pillai and D. Trejo (2005) Surface condition effects on critical chloride threshold of steel reinforcement. ACI Mater. J. 102(2):103-109

41. P. Ghods, O. B. Isgor, G. A. McRae, J. Li and G. P. Gu (2011) Microscopic investigation of mill scale and its proposed effect on the variability of chloride-induced depassivation of carbon steel rebar. Corr. Sci. 53:946-954

42. F. Yang (2017) Corrosion protection of steel embedded in new sustainable cementitious materials. PhD thesis. Politechnico Milano. Milano, Italy

43. A. J. Altayyib, M. S. Khan, I. M. Allam and A. I. Almana (1990) Corrosion Behavior of Pre-Rusted Rebars after Placement in Concrete. Cement Concrete Res 20(6):955-960

44. T. U. Mohammed and H. Hamada (2006) Corrosion of horizontal bars in concrete and method to delay early corrosion. Aci Mater J 103(5):303-311

45. S. Jäggi, B. Elsener and H. Böhni (2000) Oxygen reduction on mild steel and stainless steel in alkaline solutions, Proc. Corrosion of Reinforcement in Concrete - Corrosion Mechanism and Protection, EFC Publication No. 31, London, 3-12 
46. L. Li and A. A. Sagüés (2001) Metallurgical effects on chloride ion corrosion threshold of steel in concrete (Final Report).

47. H. B. Gunay, O. B. Isgor and P. Ghods (2015) Kinetics of Passivation and Chloride-Induced Depassivation of Iron in Simulated Concrete Pore Solutions Using Electrochemical Quartz Crystal Nanobalance. Corrosion-Us 71(5):615-627

48. N. Bouzeghaia, A. Mihi, A. Ait-Mokthar and M. Naoun (2017) Effect of passivation on chloride concentration threshold of steel reinforcement corrosion. Anti-Corrosion Methods and Materials 64:588598

49. M. Qasem, Y. Yi, S. A. Hanaei and P. Cho (2016) Electrochemical behavior of reinforcing steel for nuclear reactor containment buildings. IOSR Journal of Mechanical and Civil Engineering 13:80-90

50. M. F. Hurley and J. R. Scully (2006) Threshold chloride concentrations of selected corrosion-resistant rebar materials compared to carbon steel. Corrosion 62(10):892-904

51. B. Baroux (1995) The pitting corrosion of stainless steels - further insights. In: P. Marcus and J. Oudar (Eds.), Corrosion Mechanisms in Theory and Practice. Marcel Dekker Inc., New York 265-309.

52. B. Elsener and A. Rossi (2017) Passivation of steel and stainless steels in alkaline solutions simulating concrete. In: Encyclopedia of Interfacial Chemistry: Surface Science and Electrochemistry. Elsevier,

53. L. Bertolini, B. Elsener, P. Pedeferri, E. Redaelli and R. Polder (2013) Corrosion of Steel in Concrete: Prevention, Diagnosis, Repair (2nd Edition). WILEY VCH, Weinheim.

54. L. Li and A. A. Sagüés (2002) Chloride corrosion threshold of reinforcing steel in alkaline solutions Cyclic polarization behavior. Corrosion 58(4):305-316

55. C. Alonso, M. Castellote and C. Andrade (2002) Chloride threshold dependence of pitting potential of reinforcements. Electrochim. Acta 47:3469-3481

56. F. Presuel-Moreno, A. A. Sagüés and S. C. Kranc (2005) Steel activation in concrete following interruption of long-term cathodic polarization. Corrosion-Us 61(5):428-436

57. M. Manera, Ø. Vennesland and L. Bertolini (2008) Chloride threshold for rebar corrosion in concrete with addition of silica fume. Corros. Sci. 50(2):554-560

58. P. Ghods (2010) Multi-Scale Investigation of the Formation and Breakdown of Passive Films on Carbon Steel Rebar in Concrete. Carleton University, Canada

59. L. Bertolini and M. Gastaldi (2011) Corrosion resistance of low-nickel duplex stainless steel rebars. Mater Corros 62(2):120-129

60. R. B. Figueira, A. Sadovski, A. P. Melo and E. V. Pereira (2017) Chloride threshold value to initiate reinforcement corrosion in simulated concrete pore solutions: The influence of surface finishing and $\mathrm{pH}$. Constr Build Mater 141:183-200

61. V. Alar, G. Barsic, B. Runje and Z. Alar (2012) The influence of the surface finishing on the electrochemical behaviour of austenitic and superaustenitic steels. Materialwiss Werkst 43(8):725-732

62. C. M. Hansson and B. Sørensen (1990) The threshold concentration of chloride in concrete for the initiation of reinforcement corrosion. In: N. S. Berke, V. Chaker and D. Whiting (Eds.), Corrosion rates of steel in concrete. ASTM STP 1065, 3-16.

63. K. Pettersson (1992) Corrosion threshold value and corrosion rate in reinforced concrete. Swedish Cement and Concrete Research Institute, Stockholm.

64. P. Sandberg, K. Pettersson, H. E. Sørensen and H. Arup (1997) Critical chloride concentrations for the onset of active reinforcement corrosion. RILEM, St-Remy-Les-Chevreuses.

65. W. Breit (2001) Critical corrosion inducing chloride content - state of the art and new investigation results. Verein Deutscher Zementwerke e.V., Verlag Bau+Technik, Düsseldorf.

66. B. H. Oh, S. Y. Jang and Y. S. Shin (2003) Experimental investigation of the threshold chloride concentration for corrosion initiation in reinforced concrete structures. Mag. Concr. Res. 55(2):117-124

67. Y. LI, Y. ZHU, X. ZHU, Y. GE and L. STIRNEMANN (2007) Chloride Ion Critical Content in Reinforced Concrete. J. of Wuhan Univ. of Techn.-Mater. Sci. Ed. 22(4):737-740

68. R. Polder (2009) Critical chloride content for reinforced concrete and its relationship to concrete resistivity. Mater. Corros. 60(8):623-630

69. G. R. Meira, C. Andrade, E. O. Vilar and K. D. Nery (2014) Analysis of chloride threshold from laboratory and field experiments in marine atmosphere zone. Constr Build Mater 55:289-298

70. P. Schiessl and W. Breit (1996) Local repair measures at concrete structures damaged by reinforcement corrosion - aspects of durability. The Royal Society of Chemistry, Cambridge, UK.

71. M. Thomas (1996) Chloride threshold in marine concrete. Cem. Concr. Res. 26:513-519

72. W. Breit (1998) Kritischer korrosionsauslösender Chloridgehalt - Neuere Untersuchungsergebnisse (Teil 2). $8: 511$

73. J. S. Ryou and K. Y. Ann (2008) Variation in the chloride threshold level for steel corrosion in concrete arising from different chloride sources. Mag Concrete Res 60(3):177-187

74. R. G. Pillai, R. Gettu, M. Santhanam, S. Rengaraju, Y. Dhandapani, S. Rathnarajan and A. S. Basavaraj (2019) Service life and life cycle assessment of reinforced concrete systems with limestone calcined clay cement (LC3). Cement Concrete Res 118:111-119 
75. S. E. Hussain, A. Rasheeduzzafar, A. Al-Musallam and A. S. Al-Gahtani (1995) Factors affecting threshold chloride for reinforcement corrosion in concrete. Cem Concr Res 25:1543-1555

76. C. Monticelli, M. E. Natali, A. Balbo, C. Chiavari, F. Zanotto, S. Manzi and M. C. Bignozzi (2016) Corrosion behavior of steel in alkali-activated fly ash mortars in the light of their microstructural, mechanical and chemical characterization. Cement Concrete Res 80:60-68

77. M. Babaee and A. Castel (2018) Chloride diffusivity, chloride threshold, and corrosion initiation in reinforced alkali-activated mortars: Role of calcium, alkali, and silicate content. Cement Concrete Res 111:56-71

78. M. Holloway and J. M. Sykes (2005) Studies of the corrosion of mild steel in alkali-activated slag cement mortars with sodium chloride admixtures by a galvanostatic pulse method. Corros Sci 47(12):3097-3110

79. M. Criado and J. L. Provis (2018) Alkali Activated Slag Mortars Provide High Resistance to ChlorideInduced Corrosion of Steel. Front Mater 5

80. Q. M. Ma, S. V. Nanukuttan, P. A. M. Basheer, Y. Bai and C. H. Yang (2016) Chloride transport and the resulting corrosion of steel bars in alkali activated slag concretes. Mater Struct 49(9):3663-3677

81. S. Mundra, S. Bernal, M. Criado, P. Hlaváček, G. Ebell, S. Reinemann, G. J. Gluth and J. Provis (2017) Steel corrosion in reinforced alkali-activated materials RILEM Techn Lett 2:33-39

82. G. E. Monfore and G. J. Verbeck (1960) Corrosion of prestressed wire in concrete. J. Amer. Concr. Inst. November:491-515

83. G. K. Glass and B. Reddy (2002) The influence of the steel concrete interface on the risk of chloride induced corrosion initiation, Proc. Corrosion of Steel in Reinforced Concrete Structures, COST 521, Final Workshop, Luxembourgh, 18-19 Febrary 2002, 227-232

84. A. Castel, T. Vidal, R. François and G. Arliguie (2003) Influence of steel-concrete interface quality on reinforcement corrosion induced by chlorides. Mag. Concr. Res. 55(2):151-159

85. N. R. Buenfeld, G. K. Glass, B. Reddy and R. F. Viles (2004) Process for the protection of reinforcement in reinforced concrete, U.S. Patent 6,685,822 B2.

86. J. G. Nam, W. H. Hartt and K. Kim (2005) Effects of air void at the steel-concrete interface on the corrosion Initiation of reinforcing steel in concrete under chloride exposure. Journal of the Korea Concrete Institute 17(5):829-834

87. K. Y. Ann and N. R. Buenfeld (2007) The effect of calcium nitrite on the chloride-induced corrosion of steel in concrete. Mag Concrete Res 59(9):689-697

88. B. Reddy (2001) Influence of the steel-concrete interface on the chloride threshold level. $\mathrm{PhD}$ thesis. Imperial College, London

89. G. K. Glass, B. Reddy and L. A. Clark (2007) Making reinforcement concrete immune from chloride corrosion. Proc. Instn Civ. Engrs. - Constr. Mater. 160:155-164

90. U. Angst (2011) Chloride induced reinforcement corrosion in concrete. Concept of critical chloride content - methods and mechanisms. Norwegian University of Science and Technology, NTNU. Trondheim

91. U. Angst, C. Wagner, B. Elsener, A. Leemann and P. van Nygaard (2016) Methode zur Bestimmung des kritischen Chloridgehalts an bestehenden Stahlbetonbauwerken, Research project ASTRA AGB 2012/010, report. no. 677.

92. M. Kosalla and M. Raupach (2016) Chloride-induced depassivation of steel in concrete - influence of electrochemical potential and anodic polarization level, Proc. Service Life and Durability of Reinforced Concrete Structures, Marne-la-Vallée, France, 107-125

93. M. Kosalla and M. Raupach (2016) Potential differences between passive reinforcement segments in concrete components in dependency of binder type, aeration conditions and quality of the steel/concreteinterface. Mater Corros 67(6):639-651

94. L. W. Yu, R. François, V. H. Dang, V. L'Hostis and R. Gagne (2015) Development of chloride-induced corrosion in pre-cracked RC beams under sustained loading: Effect of load-induced cracks, concrete cover, and exposure conditions. Cement Concrete Res 67:246-258

95. J. Harnisch and M. Raupach (2011) Untersuchungen zum kritischen korrosionsauslösenden Chloridgehalt unter Berücksichtigung der Kontaktzone zwischen Stahl und Beton. Beton- und Stahlbetonbau 106(5):299307

96. A. T. Horne, I. G. Richardson and R. M. D. Brydson (2007) Quantitative analysis of the microstructure of interfaces in steel reinforced concrete. Cem. Concr. Res. 37(12):1613-1623

97. U. M. Angst, C. Boschmann, M. Wagner and B. Elsener (2017) Experimental Protocol to Determine the Chloride Threshold Value for Corrosion in Samples Taken from Reinforced Concrete Structures. Jove-J Vis $\operatorname{Exp}(126)$

98. W. Zhang, R. François and L. Yu (submitted) Influence of top-casting-induced defects on the corrosion of the longitudinal reinforcement of naturally corroded beams exposed to chloride environment under sustained loading: case of tensile reinforcement.

99. C. Gehlen and C. Sodeikat (2003) Cracked reinforced concrete: What about corrosion risk? Mater Corros 54(6):424-429

100. C. Gehlen (2004) Influence of Cracks Upon Corrosion. European Union - Fifth Framework Pro-gramme, GROWTH 2000. - Contract G1RD-CT-2000-00467, Project GRD1-25633, Report R4 of Workpackage 2.1. 
101. B. J. Pease (2010) Influence of concrete cracking on ingress and reinforcement corrosion. Ph.D thesis. Technical University of Denmark

102. C. Boschmann, U. M. Angst, M. Wagner, C. K. Larsen and B. Elsener (2017) Effect of cracks on chlorideinduced corrosion of steel in concrete - a review (NPRA report no. 454).

103. O. G. Rodriguez and R. D. Hooton (2003) Influence of cracks on chloride ingress into concrete. ACI Mater J 100(2):120-126

104. A. Michel, A. O. S. Solgaard, B. J. Pease, M. R. Geiker, H. Stang and J. F. Olesen (2013) Experimental investigation of the relation between damage at the concrete-steel interface and initiation of reinforcement corrosion in plain and fibre reinforced concrete. Corros Sci 77:308-321

105. O. Gautefall and Ø. Vennesland (1983) Effects of cracks on the corrosion of embedded steel in silicaconcrete compared to ordinary concrete. Nordic Concr. Res. 2:17-28

106. N. S. Berke, M. P. Dallaire, M. C. Hicks and R. J. Hoopes (1993) Corrosion of Steel in Cracked Concrete. Corrosion 49(11):934-943

107. P. Schiessl and M. Raupach (1997) Laboratory studies and calculations on the influence of crack width on chloride-induced corrosion of steel in concrete. ACI Mater. J. 94(1):56-62

108. R. François and G. Arliguie (1999) Effect of microcracking and cracking on the development of corrosion in reinforced concrete members. Mag Conc Res 51(2):143-150

109. T. U. Mohammed, N. Otsuki, M. Hisada and T. Shibata (2001) Effect of crack width and bar types on corrosion of steel in concrete. J Mater Civil Eng 13(3):194-201

110. G. Rehm and H. L. Moll (1964) Versuche zum Studium des Einflußes der Rissbreite auf die Rostbildung an der Bewehrung von Stahlbetonbauteilen. Deutscher Ausschuss für Stahlbeton,

111. P. Schieß1 (1976) Zur Frage der zulässigen Rissbreite und der erforderlichen Betondeckung im Stahlbetonbau unter besonderer Berücksichtigung der Karbonatisierung des Betons. Deutscher Ausschuss für Stahlbeton,

112. E. F. O’Neil (1980) Study of reinforced concrete beams exposed to marine environment. In: ACI Special Publication Nr. 65 113-132.

113. S. J. Jaffer and C. M. Hansson (2008) The influence of cracks on chloride-induced corrosion of steel in ordinary Portland cement and high performance concretes subjected to different loading conditions. Corr. Sci. 50(12):3343-3355

114. J. Pacheco (2015) Corrosion of Steel In Cracked Concrete. PhD thesis. Delft University of Technology, The Netherlands

115. J. W. Jang and I. Iwasaki (1991) Rebar Corrosion under Simulated Concrete Conditions Using Galvanic Current Measurements. Corrosion 47(11):875-884

116. M. Stefanoni, U. Angst and B. Elsener (2018) CORROSION CHALLENGES AND OPPORTUNITIES IN DIGITAL FABRICATION OF REINFORCED CONCRETE, Proc. 1st International Conference on Concrete and Digital Fabrication "Digital Concrete 2018", 10-12 September 2018, Zurich, Switzerland,

117. K. Pettersson (1996) Service life of concrete structures - in saline environment; CBI Report 3:96. CBI, Stockholm, Sweden.

118. X. Song, Q. Kong and X. Liu (2007) Experimental study on chloride threshold levels in OPC. China Civil Eng. J. 40(11):59-63

119. K. Pettersson (2018) Personal communication (23 July 2018).

120. P. Sandberg and K. Pettersson (1997) In: L.-O. Nilsson and J. P. Ollivier (Eds.), Chloride penetration into concrete. RILEM Publications, France, 453-459.

121. P. Sandberg and K. Pettersson (1997) Proc. Durability of Concrete IV, Detroit, USA, 933-947

122. P. Sandberg and H. Sørensen (1999) Factors affecting the chloride thresholds for uncracked reinforced concrete exposed in a marine environment. Part II: Laboratory- and field exposure of corrosion cells.

123. H. Arup and H. Sørensen (1997) A proposed technique for determining chloride thresholds, Proc. Chloride penetration into concrete, France, 460-469

124. P. Sandberg (1995) Critical evaluation of factors affecting chloride initiated reinforcement corrosion in concrete, Report TVBM-3068. Lund Institute of Technology, Building Materials, Lund, Sweden.

125. K. Tuutti (1982) Corrosion of steel in concrete. KTH, Kungliga Tekniska Högskolan i Stockholm. Swedish Cement and Concrete Research Institute, Stockholm, ISSN 0346-6906

126. K. Karadakis, V. J. Azad, P. Ghods and O. B. Isgor (2016) Numerical Investigation of the Role of Mill Scale Crevices on the Corrosion Initiation of Carbon Steel Reinforcement in Concrete. J Electrochem Soc 163(6):C306-C315

127. G. T. Burstein and P. C. Pistorius (1995) Surface-Roughness and the Metastable Pitting of Stainless-Steel in Chloride Solutions. Corrosion 51(5):380-385

128. M. Akhoondan and A. Sagüés (2012) Comparative Cathodic Behavior of $\sim 9 \% \mathrm{Cr}$ and Plain Steel Reinforcement in Concrete. Corrosion 68:1-10

129. J. Avilamendoza, J. M. Flores and U. C. Castillo (1994) Effect of Superficial Oxides on Corrosion of Steel Reinforcement Embedded in Concrete. Corrosion 50(11):879-885

130. M. Stefanoni, U. Angst and B. Elsener (2015) Local electrochemistry of reinforcement steel - Distribution of open circuit and pitting potentials on steels with different surface condition. Corros Sci 98:610-618 
131. G. T. Burstein and G. O. Ilevbare (1996) The effect of specimen size on the measured pitting potential of stainless steel. Corros. Sci. 38(12):2257-2265

132. L. Li and A. A. Sagüés (2004) Chloride corrosion threshold of reinforcing steel in alkaline solutions Effect of specimen size. Corrosion 60(2):195-202

133. K. Hornbostel, U. M. Angst, B. Elsener, C. K. Larsen and M. R. Geiker (2015) On the limitations of predicting the ohmic resistance in a macro-cell in mortar from bulk resistivity measurements. Cement Concrete Res 76:147-158

134. U. Angst and Ø. Vennesland (2009) Detecting critical chloride content in concrete using embedded ion selective electrodes - effect of liquid junction and membrane potentials. Mater Corros 60(8):638-643

135. A. Pourbaix (1984) Localized corrosion: behaviour and protection mechanisms, Proc. Corrosion Chemistry within Pits, Crevices and Cracks, Teddington, Middlesex, 1-15

136. U. Angst, B. Elsener, C. K. Larsen and Ø. Vennesland (2011) Chloride induced reinforcement corrosion: Rate limiting step of early pitting corrosion. Electrochim. Acta 56(17):5877-5889

137. G. T. Burstein, P. C. Pistorius and S. P. Mattin (1993) The nucleation and growth of corrosion pits on stainless steel. Corros. Sci. 35(1-4):57-62

138. P. C. Pistorius and G. T. Burstein (1992) Metastable pitting corrosion of stainless steel and the transition to stability. Philos. Trans. Royal Soc. Lond. 341:531-559

139. T. K. Tokunaga, S. Finsterle, Y. Kim, J. M. Wan, A. Lanzirotti and M. Newville (2017) Ion Diffusion Within Water Films in Unsaturated Porous Media. Environ Sci Technol 51(8):4338-4346

140. M. T. Walsh and A. A. Sagüés (2016) Steel Corrosion in Submerged Concrete Structures-Part 1: Field Observations and Corrosion Distribution Modeling. Corrosion-Us 72(4):518-533

141. M. T. Walsh and A. A. Sagüés (2016) Steel Corrosion in Submerged Concrete Structures-Part 2: Modeling of Corrosion Evolution and Control. Corrosion-Us 72(5):665-678

142. G. Fagerlund (2006) Moisture design with regards to durability - with special reference to frost destruction, . Lund University Lund, Sweden.

143. D. W. Ryu, J. W. Ko and T. Noguchi (2011) Effects of simulated environmental conditions on the internal relative humidity and relative moisture content distribution of exposed concrete. Cement Concrete Comp 33(1):142-153

144. M. Flint, A. Michel, S. L. Billington and M. R. Geiker (2014) Influence of temporal resolution and processing of exposure data on modeling of chloride ingress and reinforcement corrosion in concrete. Mater Struct 47(4):729-748

145. R. H. Relling (1999) Coastal Concrete Bridges: Moisture State, Chloride Permeability and Aging Effects. Norwegian University of Science and Technology (NTNU). Trondheim, Norway

146. F. Moro (2003) Modeling of humidity-transport in concrete. PhD thesis, no. 14984. ETH Zurich. Zurich, Switzerland

147. S. Diamond (1981) Effects of two danish flyashes on alkali contents of pore solutions of cement-flyash pastes. Cem. Concr. Res. 11:383-394

148. C. L. Page and $\varnothing$. Vennesland (1983) Pore solution composition and chloride binding capacity of silica fume-cement pastes. Mater. Struct. 19:19-25

149. K. L. Scrivener, A. K. Crumbie and P. Laugesen (2004) The interfacial transition zone (ITZ) between cement paste and aggregate in concrete. Interface Sci. 12(4):411-421

150. M. C. Alonso, J. L. García Calvo, M. Sánchez and A. 1. Fernández (2012) Ternary mixes with high mineral additions contents and corrosion related properties. Mater Corros 63(12):1078-1086

151. C. K. Larsen (1998) Chloride binding in concrete. Dr. Ing. Thesis. Norwegian University of Science and Technology, NTNU. Trondheim 